\title{
Synthesis of Li-rich NMC: a comprehensive study
}

Vanessa Pimenta, ${ }^{a}$ Mariyappan Sathiya, ${ }^{a}$ Dmitry Batuk, ${ }^{a, b}$ Artem M. Abakumov, ${ }^{c}$ Domitille Giaume, ${ }^{\mathrm{d}, \mathrm{g}}$ Sophie Cassaignon, ${ }^{\mathrm{e}, \mathrm{g}}$ Dominique Larcher, ${ }^{\mathrm{f,g}}$ and Jean-Marie Tarascon,, ${ }^{*, \mathrm{~g}, \mathrm{~h}}$

${ }^{a}$ Collège de France, Chaire de Chimie du Solide et de l'Energie, UMR 8260, 11 Place Marcelin Berthelot, 75231 Paris, France

${ }^{b}$ EMAT, University of Antwerp, Groenenborgerlaan 171, B-2020, Antwerp, Belgium

${ }^{\circ}$ Center for Electrochemical Energy Storage, Skolkovo Institute of Science and Technology, Nobel str. 3, 143026 Moscow, Russia

${ }^{d}$ Chimie Paris-Tech, PSL Research University, CNRS, IRCP, 11 rue Pierre et Marie Curie, 75231 Paris, France

${ }^{\text {e}}$ Sorbonne Universités - UPMC Univ Paris 06, UMR 7574 Chimie de la Matière Condensée de Paris, 4 place Jussieu, F-75005 Paris, France

fUniversité de Picardie Jules Verne, 80009 Amiens, France

${ }^{9}$ Réseau sur le Stockage Electrochimique de l'Energie (RS2E), FR CNRS 3459, France

${ }^{\mathrm{h}}$ Sorbonne Universités, UPMC Univ Paris 06, 4 place Jussieu, F-75005 Paris, France

*Corresponding author: jean-marie.tarascon@college-de-france.fr:

\section{Abstract}

Li-rich NMC are considered nowadays as one of the most promising candidates for high energy density cathodes. One significant challenge is nested in adjusting their synthesis conditions to reach optimum electrochemical performance, but no consensus has been reached yet on the ideal synthesis protocol. Herein we revisited the elaboration of Li-rich NMC electrodes by focusing on the science involved through each synthesis steps using carbonate $\mathrm{Ni}_{0.1625} \mathrm{Mn}_{0.675} \mathrm{Co}_{0.1625} \mathrm{CO}_{3}$ precursor co-precipitation combined with solid state synthesis. We demonstrate the effect of precursor's concentration on the kinetics of the precipitation reaction and provide clues to obtain spherically agglomerated NMC carbonates of different sizes. Moreover, we highlight the strong impact of the $\mathrm{Li}_{2} \mathrm{CO}_{3} / \mathrm{NMC}$ carbonate ratio on the morphology and particles size of Li-rich NMC and subsequently on their electrochemical performance. Ratio of 1.35 was found to reproducibly give the best performance with namely a $1^{\text {st }}$ discharge capacity of $269 \mathrm{mAh} \cdot \mathrm{g}^{-1}$ and capacity retention of $89.6 \%$ after 100 cycles. We hope that our results, which reveal how particle size, morphology and phase composition affect the material's electrochemical performance, will help in reconciling literature data while providing valuable fundamental information for up scaling approaches. 


\section{Introduction}

Since the commercialization of $\mathrm{LiCoO}_{2}$ in the early 90's, lithium-ion batteries (LIBs) have become the most important battery technology to power electronic devices and more recently electric vehicles. ${ }^{1}$ Over the years, the partial substitution of cobalt in $\mathrm{LiCoO}_{2}$ by nickel and manganese has been made to obtain materials $\mathrm{LiNi}_{1-\mathrm{y}-\mathrm{z}} \mathrm{Mn}_{\mathrm{y}} \mathrm{Co}_{\mathrm{z}} \mathrm{O}_{2}$ known as Li-NMC, which show specific capacities of $180-200$ mAh.g ${ }^{-1}$ as compared to only 150 mAh.g ${ }^{-1}$ for $\mathrm{LiCoO}_{2}{ }^{2}$ Further substituting the $3 d$-metals by $\mathrm{Li}^{+}$within the metal layers has lead to a new class of compounds $\mathrm{Li}\left(\mathrm{Li}_{x} \mathrm{Ni}_{1-x-y-z} \mathrm{Mn}_{y} \mathrm{Co}_{z}\right) \mathrm{O}_{2}$, denoted as Li-rich NMC, showing an improved capacity of 280 mAh.g ${ }^{-1}$ due to cumulative cationic and anionic redox processes. ${ }^{3,4}$ Despite such a positive attribute, commercialization of Li-rich NMC is hindered by both voltage decay upon cycling and a limited power rate ascribed to a sluggish kinetics of the anionic redox species. ${ }^{5,6,7}$ To circumvent these issues, scientists around the world have proposed numerous directions enlisting concentration gradient, surface grafting, ${ }^{8,9}$ coatings ${ }^{10,11}$ and doping. ${ }^{12,13,14}$

Prior to fully exploit these directions, it therefore remains that the preparation of pristine Lirich NMC must be better understood in light of the large spread of electrochemical data existing in the literature for samples apparently claimed to be similar. This discrepancy is illustrated by Table 1 which combines some of the reported synthesis methods and the electrochemical behavior of the resulting Li-rich NMCs. The establishment of reliable relationship between the synthesis conditions and the electrochemical performances of Li-rich NMC is needed and this calls for a complete understanding of each step involved in their synthesis process. Rather than using "ladder" experiment as usually practiced in industry for speed-wise optimization of Li-rich samples for a single $\mathrm{Ni} / \mathrm{Mn} / \mathrm{Co}$ composition we decided to embark into a comprehensive study of carbonate coprecipitation combined with solid state synthesis of Li-rich NMC and analyzed the various steps that can affect the scaling up process and reproducibility of the material synthesis. Li-rich layered compounds with different morphologies can be prepared via a wide variety of synthesis pathways including solid state, ${ }^{15}$ molten salts, ${ }^{16}$ hydrothermal, ${ }^{17}$ sol-gel $^{18}$ as well as co-precipitation in aqueous medium followed by high temperature synthesis. ${ }^{19,20}$ Among the various possible techniques, solution based co-precipitation (or aqueous sol-gel) is more viable as it can provide atomic level mixing of transition metal ions and hence homogeneity in the final oxide. Co- 
precipitation of transition metal ions can be done either as hydroxides or carbonates. Precipitation of mixed transition metal hydroxide is widely used to prepare NMC precursors. ${ }^{21,22,23}$ However, such a precipitation must be done under $\mathrm{N}_{2}$ atmosphere due to the easy oxidation of $\mathrm{Mn}^{2+}$ and $\mathrm{Co}^{2+}$ to form oxyhydroxides, hence the difficulty to control the precise stoichiometry. To eliminate the risk of such oxidation, co-precipitation as carbonate is undeniably simpler as $3 d$ metal carbonates solely exist with metals in their +2 oxidation states. We thus decided to use the carbonate co-precipitation route to prepare the NMC carbonate precursor.

Mastering the solution nucleation-growth of a precursor phase made of 3 different transition metals is a complex task. Hence, to rationalize this solution process we first explored the parameters that could influence/control the nucleation/growth of carbonate powders made of spherically agglomerated primary particles. Then, we studied the impact of the Li/M ratio ( $\mathrm{M}-$ the transition metal cations) on the Li-rich NMC materials and their electrochemical performance. From this study we not only highlight the feasibility to tailor particles of different sizes and texture (bulk vs hollow), but also reveal the importance of having the proper Li/M ratio to achieve electrochemically optimized performance. Among the prepared compounds, samples with Li/M $=1.35$ show better performance and stability upon long term cycling.

Table 1 : Characteristics of Li-rich NMC prepared by different synthetic pathways and their electrochemical behaviour.

\begin{tabular}{|c|c|c|c|c|c|c|c|}
\hline Material & $\begin{array}{l}\text { Synthetic } \\
\text { pathway/ } \\
\text { TM source }\end{array}$ & $\begin{array}{l}\text { Precursor/ } \\
\text { Li source }\end{array}$ & Morphology & Rate & $\begin{array}{c}1^{\text {st }} \\
\text { discharge } \\
\text { capacity } \\
\left(\mathrm{mAh} \cdot \mathrm{g}^{-1}\right)\end{array}$ & $\begin{array}{l}\text { Capacity } \\
\text { retention } \\
(\%)\end{array}$ & Ref. \\
\hline $\mathrm{Li}_{1.2} \mathrm{Ni}_{0.17} \mathrm{Mn}_{0.47} \mathrm{Co}_{0.16} \mathrm{O}_{2}$ & Solid state & $\mathrm{Li}_{2} \mathrm{CO}_{3}$ & Micro platelets & $15 \mathrm{~mA} / \mathrm{g}$ & 195.1 & $\begin{array}{c}92 \\
\text { (40 cycles) }\end{array}$ & 15 \\
\hline $\mathrm{Li}_{1.2} \mathrm{Ni}_{0.13} \mathrm{Mn}_{0.54} \mathrm{Co}_{0.13} \mathrm{O}_{2}$ & $\begin{array}{c}\text { Solvothermal } \\
\text { Acetates }\end{array}$ & $\begin{array}{l}\text { Carbonate/ } \\
\mathrm{LiOH} \cdot \mathrm{H}_{2} \mathrm{O}\end{array}$ & $\begin{array}{l}\text { Aggregated } \\
\text { irregular } \\
\text { nanoparticles }\end{array}$ & $0.1 \mathrm{C}$ & 289.7 & $\begin{array}{c}86.2 \\
\text { (80 cycles) }\end{array}$ & 24 \\
\hline $\mathrm{Li}_{1.2} \mathrm{Ni}_{0.13} \mathrm{Mn}_{0.54} \mathrm{Co}_{0.13} \mathrm{O}_{2}$ & $\begin{array}{l}\text { Co-precip. } \\
\text { Acetates }\end{array}$ & $\begin{array}{l}\text { Carbonate/ } \\
\mathrm{LiOH} \cdot \mathrm{H}_{2} \mathrm{O}\end{array}$ & $\begin{array}{c}\text { Nanometric } \\
\text { irregular } \\
\text { particles }\end{array}$ & $0.1 \mathrm{C}$ & 267.5 & $\begin{array}{c}80.9 \\
\text { (80 cycles) }\end{array}$ & 24 \\
\hline $\mathrm{Li}_{1.2} \mathrm{Ni}_{0.13} \mathrm{Mn}_{0.54} \mathrm{Co}_{0.13} \mathrm{O}_{2}$ & $\begin{array}{l}\text { Co-precip. } \\
\text { Sulfates }\end{array}$ & $\begin{array}{l}\text { Carbonate/ } \\
\mathrm{LiOH} \cdot \mathrm{H}_{2} \mathrm{O}\end{array}$ & $\begin{array}{c}\text { Irregular } \\
200-500 \mathrm{~nm}\end{array}$ & $0.1 \mathrm{C}$ & 233.5 & $\begin{array}{c}76.2 \\
\text { (50 cycles) }\end{array}$ & 25 \\
\hline $\mathrm{Li}_{1.2} \mathrm{Ni}_{0.12} \mathrm{Mn}_{0.56} \mathrm{Co}_{0.12} \mathrm{O}_{2}$ & $\begin{array}{c}\text { Solvothermal } \\
\text { Acetates + } \\
\text { Nitrates }\end{array}$ & $\begin{array}{l}\text { Carbonate/ } \\
\mathrm{LiOH} \cdot \mathrm{H}_{2} \mathrm{O}\end{array}$ & Microspheres & $0.5 \mathrm{C}$ & 236.7 & $\begin{array}{c}89.1 \\
\text { (100 cycles) }\end{array}$ & 26 \\
\hline
\end{tabular}




\begin{tabular}{|c|c|c|c|c|c|c|c|}
\hline $\mathrm{Li}_{1.2} \mathrm{Ni}_{0.12} \mathrm{Mn}_{0.56} \mathrm{Co}_{0.12} \mathrm{O}_{2}$ & $\begin{array}{c}\text { Solvothermal } \\
\text { Acetate }\end{array}$ & $\mathrm{LiCOOCH}_{3}$ & Microrods & $0.5 \mathrm{C}$ & 264.6 & $\begin{array}{c}91.1 \\
\text { (100 cycles) }\end{array}$ & 26 \\
\hline $\mathrm{Li}_{1.2} \mathrm{Ni}_{0.12} \mathrm{Mn}_{0.56} \mathrm{Co}_{0.12} \mathrm{O}_{2}$ & $\begin{array}{l}\text { Co-precip. } \\
\text { Sulfates }\end{array}$ & $\mathrm{LiOH} \cdot \mathrm{H}_{2} \mathrm{O}$ & nanoplates & $0.5 \mathrm{C}$ & 209.8 & $\begin{array}{c}83.3 \\
\text { (100 cycles) }\end{array}$ & 26 \\
\hline $\mathrm{Li}_{1.2} \mathrm{Ni}_{0.12} \mathrm{Mn}_{0.56} \mathrm{Co}_{0.12} \mathrm{O}_{2}$ & $\begin{array}{c}\text { Hydrothermal } \\
\text { Acetates }\end{array}$ & $\begin{array}{c}\text { Oxalate/ } \\
\text { LiOH }\end{array}$ & $\begin{array}{l}\text { Irregular shape } \\
1 \mu \mathrm{m}\end{array}$ & $0.5 \mathrm{C}$ & 156.3 & $\begin{array}{c}80.9 \\
\text { (100 cycles) }\end{array}$ & 26 \\
\hline $\mathrm{Li}_{1.2} \mathrm{Ni}_{0.13} \mathrm{Mn}_{0.54} \mathrm{Co}_{0.13} \mathrm{O}_{2}$ & $\begin{array}{c}\text { Molten salt } \\
\mathrm{MnO}_{2}+ \\
\text { Acetates }\end{array}$ & $\mathrm{LiOH} \cdot \mathrm{H}_{2} \mathrm{O}$ & $\begin{array}{c}\text { Hollow } \\
\text { microspheres } \\
1-1.5 \mu \mathrm{m}\end{array}$ & $0.1 \mathrm{C}$ & 296 & - & 27 \\
\hline $\mathrm{Li}_{1.2} \mathrm{Ni}_{0.1} \mathrm{Mn}_{0.6} \mathrm{Co}_{0.1} \mathrm{O}_{2}$ & $\begin{array}{l}\text { Co-precip. } \\
\text { Sulfates }\end{array}$ & $\begin{array}{c}\text { carbonate } \\
\mathrm{LiOH}\end{array}$ & $\begin{array}{c}\text { Hollow } \\
\text { microspheres } \\
5-6 \mu \mathrm{m}\end{array}$ & $50 \mathrm{~mA} / \mathrm{g}$ & 242 & $\begin{array}{c}74 \\
\text { (35 cycles) }\end{array}$ & 28 \\
\hline $\mathrm{Li}_{1.2} \mathrm{Ni}_{0.13} \mathrm{Mn}_{0.54} \mathrm{Co}_{0.13} \mathrm{O}_{2}$ & $\begin{array}{c}\text { Molten salt } \\
\mathrm{MnO}_{2}+ \\
\text { Acetates }\end{array}$ & $\mathrm{LiOH} \cdot \mathrm{H}_{2} \mathrm{O}$ & $\begin{array}{c}\text { Hollow } \\
\text { microspheres } \\
1 \mu \mathrm{m}\end{array}$ & $0.1 \mathrm{C}$ & 309.9 & $\begin{array}{c}74 \\
\text { (35 cycles) }\end{array}$ & 29 \\
\hline $\mathrm{Li}_{1.2} \mathrm{Ni}_{0.13} \mathrm{Mn}_{0.54} \mathrm{Co}_{0.13} \mathrm{O}_{2}$ & $\begin{array}{c}\text { Hydrothermal } \\
\text { Acetates }\end{array}$ & $\mathrm{LiCOOCH}_{3}$ & Microrods & $0.1 \mathrm{C}$ & 280.7 & $\begin{array}{c}87.5 \\
\text { (50 cycles) }\end{array}$ & 30 \\
\hline $\mathrm{Li}_{1.2} \mathrm{Ni}_{0.13} \mathrm{Mn}_{0.54} \mathrm{Co}_{0.13} \mathrm{O}_{2}$ & $\begin{array}{c}\text { Sol-gel } \\
\text { Acetates }\end{array}$ & $\mathrm{LiCOOCH}_{3}$ & $\begin{array}{c}\text { Round-shaped } \\
\text { nanoparticles } \\
100-250 \mathrm{~nm}\end{array}$ & $0.1 \mathrm{C}$ & 277.3 & $\begin{array}{c}98.4 \\
\text { (50 cycles) }\end{array}$ & 31 \\
\hline
\end{tabular}

\section{Experimental}

Carbonate precursors were prepared by a co-precipitation method in presence of a chelating agent. The $\mathrm{Li}$-rich materials were obtained from a mixture of carbonate precursor and $\mathrm{Li}_{2} \mathrm{CO}_{3}$ after two annealing steps.

The powder X-ray diffraction (XRD) patterns were recorded using Bruker D8 advance diffractometer with $\mathrm{Cu} \mathrm{K}_{\alpha}$ radiation source. The XRD patterns were collected between $2 \theta=15-80^{\circ}$ with a step of $0.013^{\circ}$ and refined using FullProf software. ${ }^{32,33}$ The elemental composition of carbonate precursors and Li-rich NMC oxides were verified with ICP-AES in a ThermoFisher iCAP 6000 device. For this experiment, carbonate samples were digested in $\mathrm{HNO}_{3}$ while Li-rich $\mathrm{NMC}$ required a treatment with an aqua regia (mixture of concentrated $\mathrm{HNO}_{3}$ and $\mathrm{HCl}$ in the molar ratio of $1: 3)$. The size and morphology of the particles were observed by scanning electron microscopy performed in Hitachi S-3400N and FEI Quanta FEG 250 microscopes. Energy dispersive X-ray (EDX) analysis was performed using an Oxford X-Max detector (accelerating voltage: $10 \mathrm{keV}$ ). Size distribution histograms were plotted with ImageJ software ${ }^{34}$ by analyzing SEM images covering 300- 400 particles.

Transmission electron microscopy (TEM) samples were prepared in a glove box by crushing the crystals using a mortar in anhydrous dimethyl carbonate (DMC) and depositing drops of 
suspension onto holey carbon grids. The samples were transported to the microscope column completely excluding contact with air. Electron diffraction (ED) patterns, high angle annular dark field scanning transmission electron microscopy (HAADF-STEM) images and annular bright field STEM (ABF-STEM) images were obtained with aberration-corrected Titan $\mathrm{G}^{3}$ electron microscopes operated at 200 and $300 \mathrm{kV}$.

The electrochemical properties of the prepared samples were tested in CR2032 coin cells, assembled in an argon-filled glove box. The positive electrode films were prepared from a mixture of $80 \%$ active material (Li-rich NMC), $10 \%$ carbon conducting additive and 10\% PVDF (polyvinylidine fluoride) binder (w/w). The slurry was made using NMP (N-methyl pyrrolidine) solvent, stirred overnight, casted in aluminum foil and then dried in vacuum at $80^{\circ} \mathrm{C}$ for $12 \mathrm{~h}$. A constant thickness of $\sim 150 \mu \mathrm{m}$ with a loading of $\sim 5 \mathrm{mg} / \mathrm{cm}^{2}$ is used. Lithium metal foil stuck to the stainless steel current collector was used as negative electrode. The LP100 (LiPF 1 mol.L-1 in $\mathrm{EC} / \mathrm{PC} / \mathrm{DMC}$ 1:1:3) electrolyte is used to have improved stability in the high voltage region (4.8 V). All the charge-discharge cycles were performed between 4.8-2 $\mathrm{V}$ and the cells were tested in a Biologic cycler.

\section{Results and discussion}

Li-rich NMCs have been heavily explored to determine the proper Ni: Mn: Co ratio to achieve the best electrochemical performance and the results have converged towards $\mathrm{Li}\left(\mathrm{Li}_{0.2} \mathrm{Ni}_{0.13} \mathrm{Mn}_{0.54} \mathrm{Co}_{0.13}\right) \mathrm{O}_{2}$ as the best composition in terms of capacity. ${ }^{8,35}$ Hence we decided to focus on this specific composition for studying the synthesis mechanisms. First, we started with the co-precipitation of the precursor carbonate $\mathrm{Ni}_{0.13} \mathrm{Mn}_{0.54} \mathrm{Co}_{0.13}\left(\mathrm{CO}_{3}\right)_{0.8}$ which can be written as $\mathrm{Ni}_{0.1625} \mathrm{Mn}_{0.675} \mathrm{Co}_{0.1625} \mathrm{CO}_{3}$. For simplicity reasons, $\mathrm{Li}\left(\mathrm{Li}_{0.2} \mathrm{Ni}_{0.13} \mathrm{Mn}_{0.54} \mathrm{CO}_{0.13}\right) \mathrm{O}_{2}$ and the precursor carbonate $\mathrm{Ni}_{0.1625} \mathrm{Mn}_{0.675} \mathrm{CO}_{0.1625} \mathrm{CO}_{3}$ will be termed hereafter as Li-rich $\mathrm{NMC}$ and $\mathrm{NMC}$ carbonate respectively.

The syntheses of transition metal carbonates were performed in an automated tank reactor (CSTR) which allows a strict control of all parameters influencing the particles morphology, such as temperature, $\mathrm{pH}$, stirring speed and adding rate. Initially, the $2 \mathrm{~L}$ tank reactor was filled with 800 $\mathrm{mL}$ of water before the addition of transition metal sulfates and the precipitator $\mathrm{Na}_{2} \mathrm{CO}_{3}($ sodium 
carbonate). The transition metal sulfates $\mathrm{NiSO}_{4} \cdot 6 \mathrm{H}_{2} \mathrm{O}$ (nickel (II) sulphate hexa hydrate, Aldrich), $\mathrm{MnSO}_{4} \cdot \mathrm{H}_{2} \mathrm{O}$ (manganese (II) sulphate monohydrate, Aldrich) and $\mathrm{CoSO}_{4} \cdot 7 \mathrm{H}_{2} \mathrm{O}$ (cobalt (ii) sulphate hepta hydrate, Aldrich) were dissolved in distilled water to prepare a $2 \mathrm{~mol}^{-1} \mathrm{~L}^{-1}$ solution with the $\mathrm{Ni}$ : Mn: Co stochiometric ratio of 0.1625: 0.675: 0.1625 .

A second solution, containing 2 mol. $\mathrm{L}^{-1} \quad \mathrm{Na}_{2} \mathrm{CO}_{3}$ and $0.2 \mathrm{~mol} \cdot \mathrm{L}^{-1} \quad \mathrm{NH}_{3} \cdot \mathrm{H}_{2} \mathrm{O}$ acting as a precipitator and a chelating agent, respectively, was prepared. Ammonia is specially used herein to help the formation of spherical particles that are highly desirable for achieving high packing density and hence high energy density cathodes. More precisely, the CSTR's temperature was maintained at $55{ }^{\circ} \mathrm{C}$ during the precipitation step with a $\mathrm{pH}$ settled at $7.5 / 8$ and the stirring speed fixed at 1000 rpm. Metal sulfates solution was added at a constant rate of $45 \mathrm{~mL} / \mathrm{h}$, while $\mathrm{Na}_{2} \mathrm{CO}_{3} / \mathrm{NH}_{3}$ solution was dynamically added to maintain the solution $\mathrm{pH}$ between $7.5-8$ as the $\mathrm{pH}$ of greater than 8 tends to form $\mathrm{Ni}(\mathrm{OH})_{2}$ secondary phase.

To get insights in the formation of carbonate spherical particles, we monitored the kinetics of the precipitation reaction by collecting samples each 5 minutes from the beginning of the reaction until 60 minutes and then every 15 minutes till 75, 90, 105 and 120 minutes. Fig. 1 (a) shows the SEM images of the precipitated particles as a function of time. Note that a time of 30 minutes is necessary to trigger the first spherical particles whose population keeps increasing with time afterwards (Fig. 1a). The chemical composition of the precipitates was deduced by means of both EDX and ICP analysis, with the latter being solely feasible beyond 35 minutes, time necessary to reach enough amounts of precipitate. Both techniques indicate that the expected global composition of $0.1625 \mathrm{Ni}$ : $0.675 \mathrm{Mn}$ : $0.1625 \mathrm{Co}$ is reached after $50 \mathrm{~min}$ of reaction and is maintained throughout the reaction and also in the recovered final product. This contrasts with the beginning of the reaction, since EDX analysis on the particles recovered after 15 minutes shows a higher amount of nickel, which reduces at the expense of an increase in cobalt and manganese contents with increasing time till 30 minutes (Fig. $1 \mathrm{~b}$ (left)). This shows that nickel ions are the first to precipitate out from the solution and therefore most likely act as nucleation centers. Such progressive precipitation of $\mathrm{Ni}$, Co and then manganese matches well with the change in color from green to olive green and pink with time (inset in Fig. 1(b)). 


\section{a}
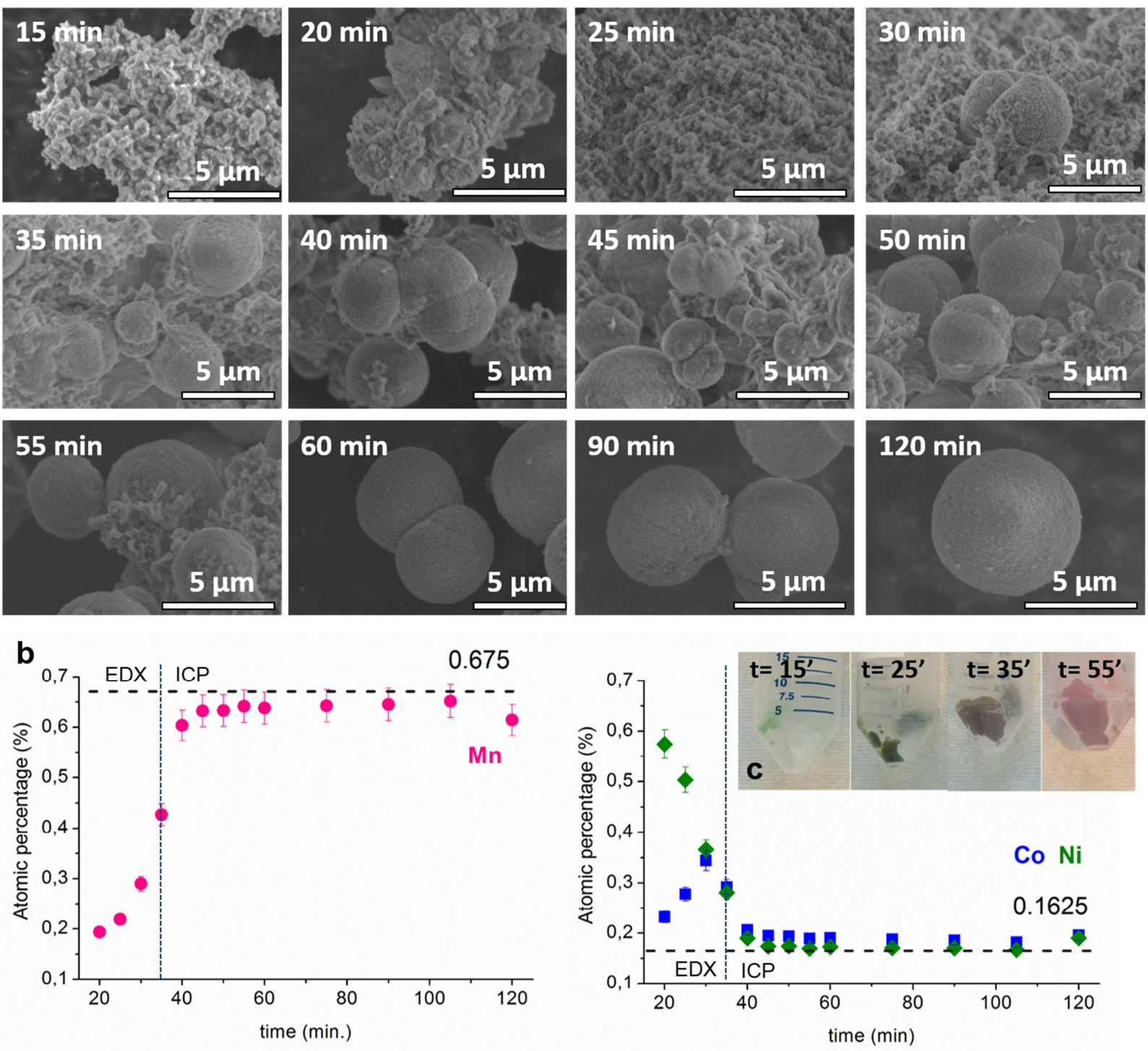

Fig. 1 : SEM images of the samples collected at different precipitation time (a); Atomic percentages (\%) of the samples collected at different precipitation time (b); Colour evolution of the collected samples (c).

In light of these time-driven morphology and chemical composition changes we have schematized (Fig. 2) the precipitation process evolution as follows. Initially divalent transition metal cations are in the aquo-complex configuration $\left[\mathrm{M}\left(\mathrm{H}_{2} \mathrm{O}\right)_{6}\right]^{2+}$ as expected by being in aqueous media. After 10 minutes, the solution appears to be light green but no solid can be recovered. Hence, all cations are still in solution, however the green color may be due to the formation of some soluble complexes having $\mathrm{NH}_{3}$ ligands (Fig. 2a). Fifteen minutes are indeed necessary to trigger the beginning of the precipitation as visualized by the appearance of a light green solid. Until 25 minutes the collected powders are green nuclei with irregular shape, appearing as thin platelets 
with no hierarchical organisation. The layered morphology of the primary seeds suggests that nickel hydroxide is most likely forming at first. Nevertheless, another possibility is the formation of $2 \mathrm{NiCO}_{3} \cdot 3 \mathrm{Ni}(\mathrm{OH})_{2} \cdot 4 \mathrm{H}_{2} \mathrm{O}$, since $\mathrm{Ni}(\mathrm{OH})_{2}$ dissolves in ammonia, forming nickel amine complexes that in presence of $\mathrm{Na}_{2} \mathrm{CO}_{3}$ could form the basic green carbonate. ${ }^{36}$

After 30 minutes the color of the precipitate changes from green to olive green implying a progressive evolution in the elemental composition with time (Fig. 1c). Through this time period we equally noted an evolution of the XRD patterns, initially featureless, which start to show a few broad and weak peaks that we could attribute to both carbonate and $\mathrm{Ni}(\mathrm{OH})_{2}$ (Fig. S2). This led us to believe that $\mathrm{Ni}(\mathrm{OH})_{2}$ acts as the nucleation seeds, whose growth and metal composition evolution with time finally leads to the target NMC carbonate. The increasing surface tension causes after nearly 30 minutes a hierarchisation of the primary particles in spheres by an oriented attachement mechanism. This lead to the formation of secondary spherical agglomerates composed of nanometric primary thin platelet particles as observed in Fig. 2b. Moreover note that the thin platelets do not organise as individual spherical entities but mostly as dual particules around a central crystallization point/plane. After nearly 50 minutes, when the desired global elemental composition (deduced from ICP) is reached, the precipitate changes to a light pink color. However, the powders are inhomogeneous in terms of size as they are composed of both shapeless and individual spherical particles, with the latter growing at the expense of the small ones implying an Ostwald ripening (Fig. 2c). The increase in crystallinity observed from XRD pattern (Fig. S2) with reaction time further confirms the Ostwald ripening mechanism. Through such a growth, two entities (twin spheres shown in Fig. 2c) sharing the same nucleation plane enlarge continuously, reaching an average overall size of $\sim 10 \mu \mathrm{m}$. The twin spheres cleave due to geometric hindrance along their native plane to produce spherical particles whose surface is further smoothed by Ostwald ripening. The final carbonate powder, mainly made of smooth spherical particles, shows a trigonal $R \overline{3} c \mathrm{CaCO}_{3}$-type structure (Fig. S3). Broad peaks indicate the presence of nanometric-sized crystallites corresponding to the previously mentioned primary particles. Lastly it is worth mentioning that although quite spectacular, the formation of twin spheres from platelets and their splitting, as presently observed here, is not new. There are many 
antecedents in the literature with namely the growth of $\mathrm{CaCO}_{3}$ from the solution or other oxide electrodes. $^{37,38,39}$

a

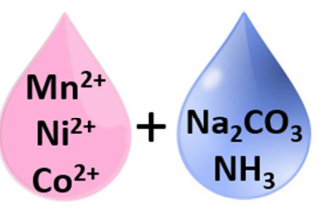

$\mathrm{T}=55^{\circ} \mathrm{C}, \mathrm{pH} 8$ 10 min. $\downarrow$ Complexation

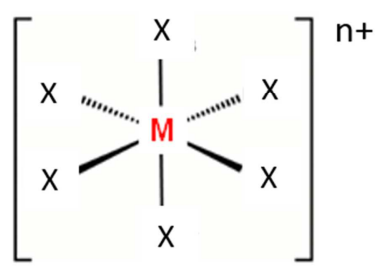

$\mathrm{M}=\mathrm{Mn}^{2+}, \mathrm{Ni}^{2+}, \mathrm{Co}^{2+}$

$\mathbf{X}=\mathrm{OH}^{-}$or $\mathrm{NH}_{3}$

Metal-ammonium complexes

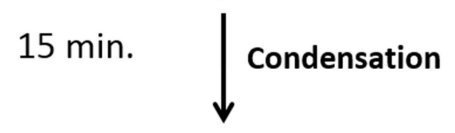

$\mathrm{Ni}$ rich seeds nucleation

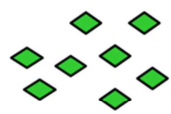

No hierarchization

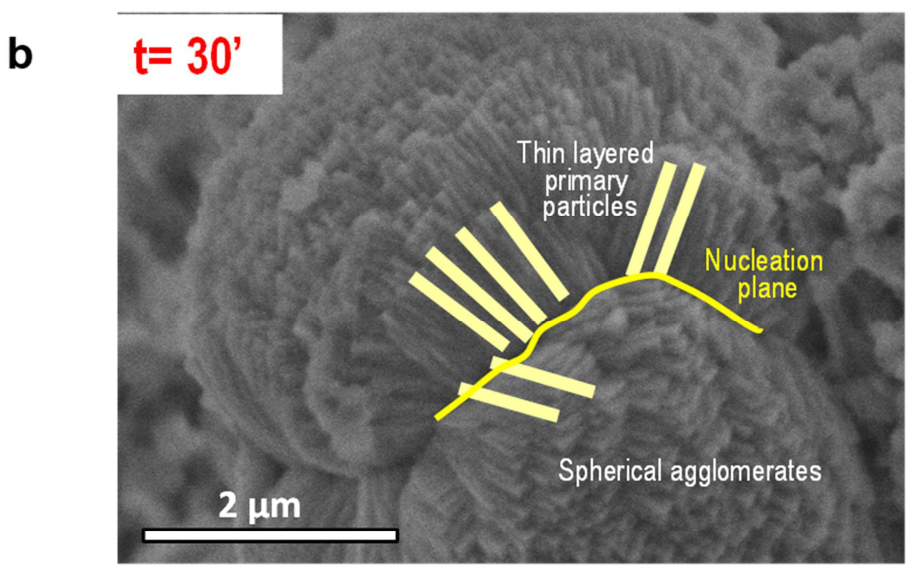

C
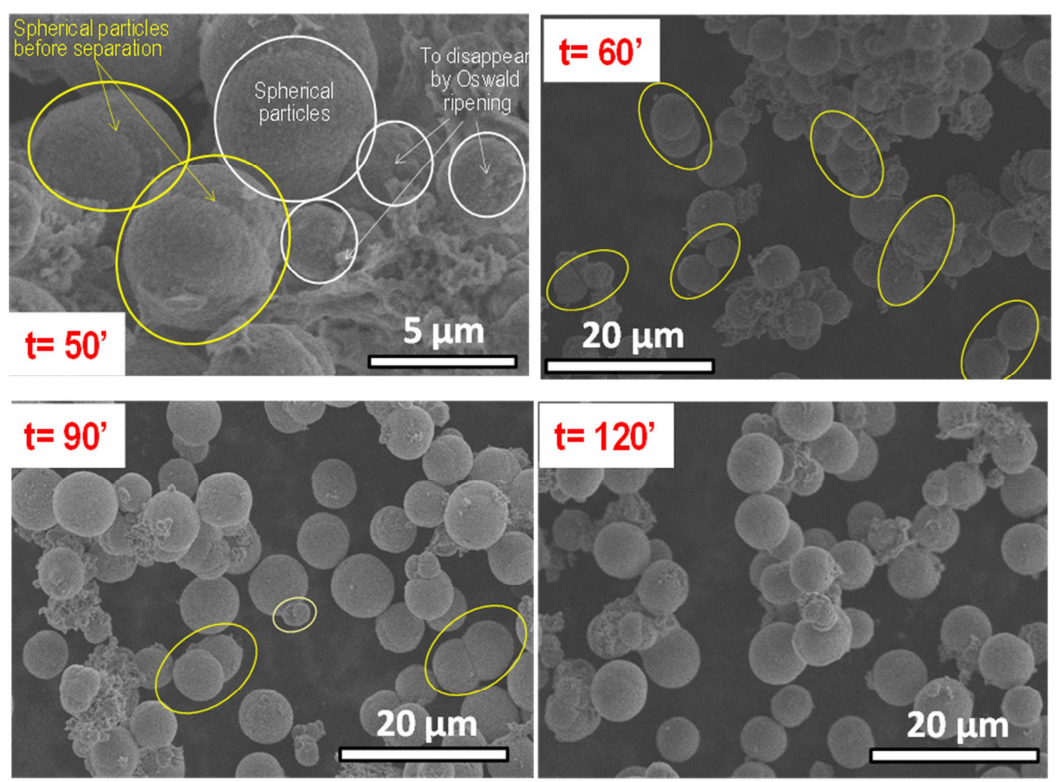

Fig. 2 : Schematic illustration of the precipitation process of the spherical carbonate micro-particles: formation of the layered seeds (a); spherical secondary particle composed by nanoplatelets (b); growing mechanism of the spherical particles (c).

To show the robustness of this proposed precipitation path, we have checked the effect of maturation time and found that extending the maturation time to 4, 8, 12 and 16 hours constantly lead to spherical particles of $5 \mu \mathrm{m}$ with a smooth surface (Fig. 3a), implying that maturation time cannot be used as an extra parameter to tune the particle size of the NMC carbonate. However, it is to be remembered that, while the overall composition is reached at $50 \mathrm{~min}$, a minimum of 4 hours is therefore necessary to reach homogeneous monodispersed spherical particles with the 
composition $\mathrm{Ni}_{0.1625} \mathrm{Mn}_{0.675} \mathrm{Co}_{0.1625} \mathrm{CO}_{3}$ (Fig. 3b). In light of this finding, we decided if not otherwise specified to use a maturation time of 12 hours for all our samples.
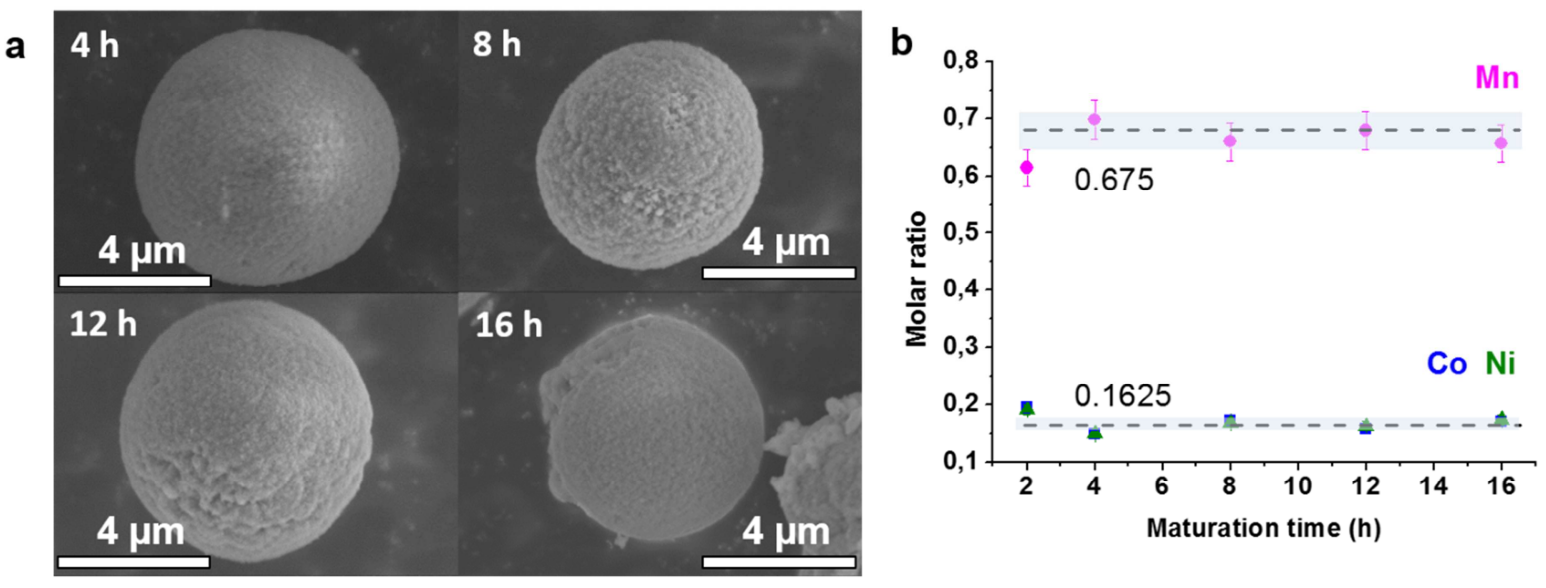

Fig. 3 : SEM images of the carbonate samples collected at different maturation time (a); atomic percentages (\%) of respective samples (b).

Lastly, the effect of concentration was considered by preparing two different concentrations $0.1 \mathrm{~mol} . \mathrm{L}^{-1}$ and $0.4 \mathrm{~mol} . \mathrm{L}^{-1}$ (by using $50 \mathrm{~mL}$ and $250 \mathrm{~mL}$ of the $2 \mathrm{~mol} . \mathrm{L}^{-1}$ metal sulfate precursor solutions to get NMC carbonate of $10 \mathrm{~g}$ and $50 \mathrm{~g}$ respectively) while maintaining the maturation time for 12 h. Both carbonates were shown to have the expected stoichiometry $\mathrm{Ni}_{0.1625} \mathrm{Mn}_{0.675} \mathrm{Co}_{0.1625} \mathrm{CO}_{3}$ therefore populated with larger particles of $9 \pm 1 \mu \mathrm{m}$ size for the $0.4 \mathrm{~mol} . \mathrm{L}^{-1}$ sample as opposed to $7 \pm 1 \mu \mathrm{m}$ for $0.1 \mathrm{~mol}^{-\mathrm{L}^{-1}}$ bath (Fig. 4 and see histograms in Fig. S4).

Once the carbonate precipitates are recovered, they were abundantly washed with water to eliminate sulfate and sodium residues and dried at $80^{\circ} \mathrm{C}$ under vacuum for $12 \mathrm{~h}$ prior preparing $\mathrm{Li}$ rich NMC by adding the proper amount of $\mathrm{Li}_{2} \mathrm{CO}_{3}$. The multi-component powders were softly ground with mortar and pestle for 15 minutes to keep the particles spherical morphology prior to heat the homogeneous mixture to $500^{\circ} \mathrm{C}$ for $5 \mathrm{~h}$, re-ground for 15 minutes and then annealed at $850^{\circ} \mathrm{C}$ for $12 \mathrm{~h}$ under air. 

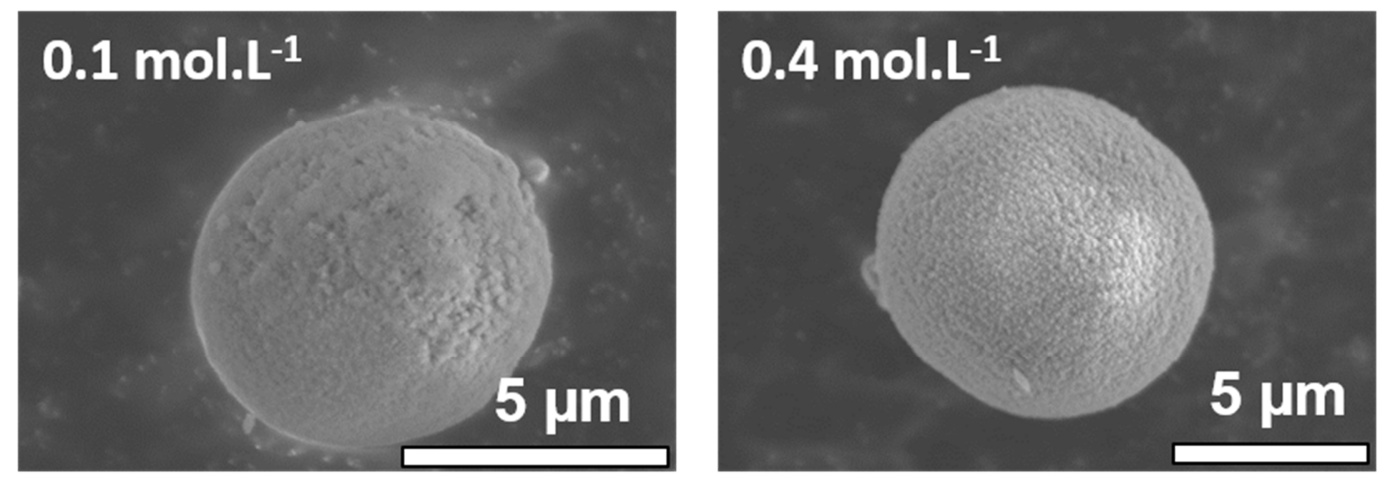

Fig. 4 : SEM images of the carbonate samples prepared at two concentrations, 0.1 mol. $\mathrm{L}^{-1}$ and $0.4 \mathrm{~mol} . \mathrm{L}^{-1}$.

\section{$\mathrm{Li} / \mathrm{M}$ ratio variation and impact on morphology}

Among the Li-rich compounds, the composition $\mathrm{Li}_{1.2} \mathrm{Ni}_{0.13} \mathrm{Mn}_{0.54} \mathrm{Co}_{0.13} \mathrm{O}_{2}(\mathrm{Li} / \mathrm{M}=1.5)$ has so far being the most investigated with great efforts devoted towards sensing the effect of various synthesis parameters (temperature, quenching, Li source) ${ }^{15,40,41}$ on the electrode performance. In contrast, according to our knowledge, the effect of the Li/M ratio has not been intensively studied in great details. ${ }^{42,43}$ To unveil the impact of this parameter, two sets of samples with Li/M ratio equal to $1.2,1.35,1.5,1.65$ and 1.8 , were prepared using the previously described $0.1 \mathrm{~mol}^{-1}$ and 0.4 mol. $\mathrm{L}^{-1} \mathrm{NMC}$ carbonates batches and $\mathrm{Li}_{2} \mathrm{CO}_{3}$. Powder mixtures, made by maintaining the amount of $\mathrm{NMC}$ carbonate as a fixed parameter and varying the amount of $\mathrm{Li}_{2} \mathrm{CO}_{3}$, were heat treated to produce $\mathrm{Li}_{\times} \mathrm{Ni}_{0.13} \mathrm{Mn}_{0.54} \mathrm{CO}_{0.13} \mathrm{O}_{2}$ samples which were characterized for their composition and structure prior to electrochemical tests. ICP analysis has shown that the chemical composition of the recovered Li-rich NMC samples are perfectly in line with their nominal compositions implying the absence of any chemical volatilization through the heating process.

The XRD patterns of the samples with different Li/M ratio (Fig. 5) show well crystallized phases with sharp and intense peaks. All of them could be indexed in the monoclinic $C 2 / m$ space group (Fig. S5) which fully take into account the superstructure peaks in the $2 \theta=20-35^{\circ}$ range. For the Li/M ratios of 1.2 and 1.35 the superstructure peaks appear as a broad band and only the 020 reflection can be clearly distinguished, suggesting numerous stacking faults between the "honeycomb" Li-rich layers. Moreover, the Li/M = 1.2 pattern shows a small shoulder near the 111 and 131 reflections, indicating a presence of the spinel phase $\mathrm{LiMn}_{2} \mathrm{O}_{4}$. This extra phase does not 
come as a total surprise since for $\mathrm{Li} / \mathrm{M}=1.2$ or even 1.35 , there is not enough $\mathrm{Li}$ to form $\mathrm{Li}_{1.2} \mathrm{Ni}_{0.13} \mathrm{Mn}_{0.54} \mathrm{Co}_{0.13} \mathrm{O}_{2}$, but solely $\mathrm{Li}_{0.96} \mathrm{Ni}_{0.13} \mathrm{Mn}_{0.54} \mathrm{Co}_{0.13} \mathrm{O}_{2}$, so that we favour the formation of $\mathrm{a}$ second phase having a $\mathrm{Li} / \mathrm{M}$ of 0.5 which coexists with the layered $\mathrm{Li}_{1.2}$ phase. With increasing the $\mathrm{Li} / \mathrm{M}$ ratio $(\geq 1.5)$, the sample's crystallinity increases with the emergence of well-defined superstructure peaks that implies a better stacking order between the adjacent honeycomb-like $\mathrm{LiM}_{2}$ layers. Lastly, weak diffraction peaks corresponding to $\mathrm{Li}_{2} \mathrm{CO}_{3}$ can be observed as expected for the $\mathrm{Li} / \mathrm{M}=1.8$ sample having $\mathrm{Li}$ in excess. Whatever the set of carbonate precursors used $(0.1$ or $0.4 \mathrm{~mol} . \mathrm{L}^{-1}$ ), both series of samples show similar behavior implying the robustness of the observed trends.
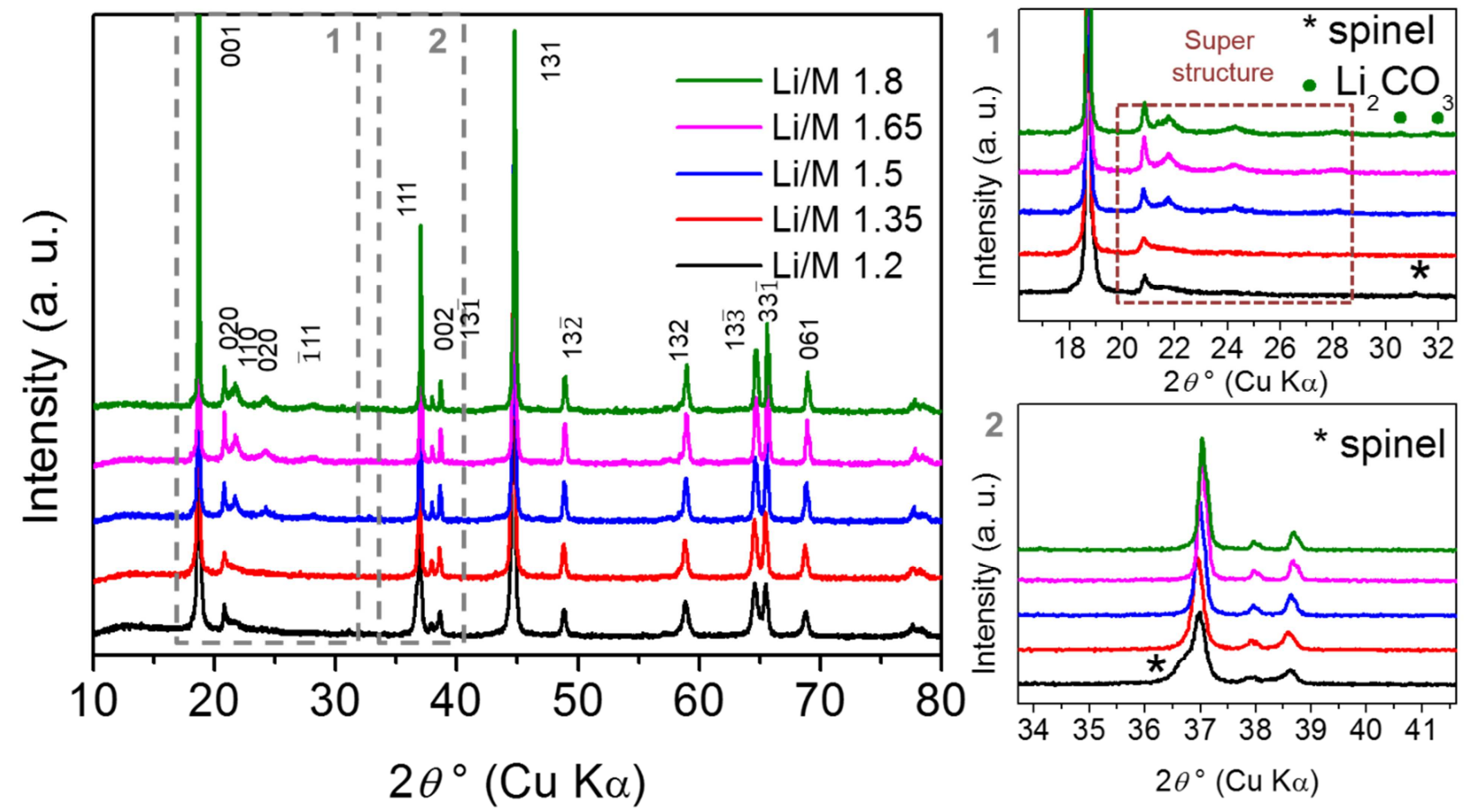

Fig. 5 : Powder XRD patterns of the Li-rich compounds with different Li/M ratio (left); zooms of the $2 \theta=16$ 32.5 region (top right) and $2 \theta=33-42$ region (bottom right).

SEM investigations reveal that the size of the secondary particles (e.g spheres) is independent of the amount of $\mathrm{Li}_{2} \mathrm{CO}_{3}$ as long as the samples are made from the same NMC carbonate batch (Fig. 6), but it is more affected by the type of NMC batch used, since particles obtained from the $0.4 \mathrm{~mol} . \mathrm{L}^{-1}$ batch are slightly bigger than the ones from the $0.1 \mathrm{~mol} . \mathrm{L}^{-1}$ batch. It is 
also worth to note that even at higher amounts of $\mathrm{Li}_{2} \mathrm{CO}_{3}$ the spherical morphology is kept, in opposition to already reported studies. ${ }^{43}$ In contrast, drastic differences in the primary particles can be observed depending upon the Li/M ratio.

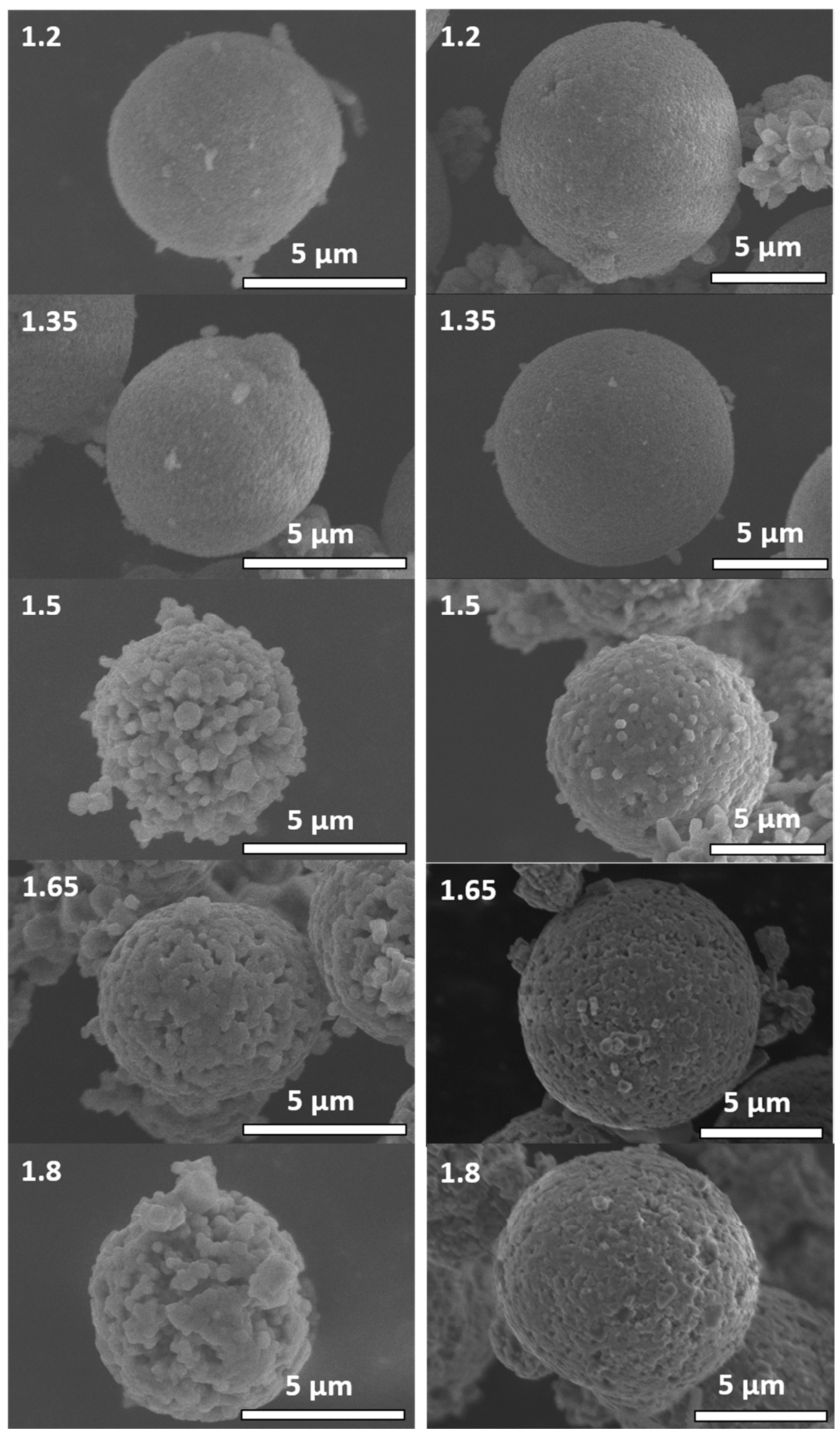

Fig. 6 : Li-rich NMC synthetized with different Li/M ratios at two different concentrations: $0.1 \mathrm{~mol}^{-\mathrm{L}^{-1}}$ (left) and $0.4 \mathrm{mol.} \mathrm{L}^{-1}$ (right). 
Spherical agglomerates in the samples with the Li/M ratio of 1.2 and 1.35 have rather smooth surface (Fig. 7a) and demonstrate a complex hierarchical structure. The spheres consist of thin rods propagating from the center of the sphere towards its surface (Fig. S6 and Fig. 7b). The thickness of the rods is about $\sim 100-200 \mathrm{~nm}$, but the length could reach whole radius of the agglomerate (i.e. $1-2 \mu \mathrm{m}$ ). The rods in turn are composed of the rhombus-like nanocrystals with the size of $\sim 50 \mathrm{~nm}$ (Fig. $7 \mathrm{~b})$.

The spherical agglomerates in the $\mathrm{Li} / \mathrm{M}=1.5,1.65$ and 1.8 samples demonstrate more rough and irregular surface due to coarsening of the constituting crystallites (Fig. S6, Fig. 7c, e). Now the spheres are composed of large rod-like crystals looking like distorted hexagons in cross-section with the diameter up to $500 \mathrm{~nm}$ and length up to $1 \mu \mathrm{m}$ (Fig. $7 \mathrm{~d}, \mathrm{f}$ ). The longest dimension of these crystals is still oriented from the center of the sphere towards its surface. Spheres in these samples are hollow, in contrast to the spheres in the $\mathrm{Li} / \mathrm{M}=1.2,1.35$ samples.

The increase in crystallite size with increasing the Li/M ratio can be explained by the large excess of $\mathrm{Li}_{2} \mathrm{CO}_{3}$ which acts as a flux (melting point $723^{\circ} \mathrm{C}$ ) and assists crystal growth during the synthesis process. ${ }^{44} \mathrm{~A}$ formation of the hollow spheres during the growth process can be attributed to the Kirkendall effect that occurs during the annealing steps. The transition metals rapidly migrate outwards to react with $\mathrm{Li}$ to form the Li-rich compound. Meanwhile a part of the oxygen atoms slowly diffuses inward, while the other part of volatile atoms/molecules $\left(\mathrm{O}_{2}, \mathrm{CO}_{2}\right)$ is released as gas. The hollow at the interior of the micro-spheres is then formed. ${ }^{27,45}$ 


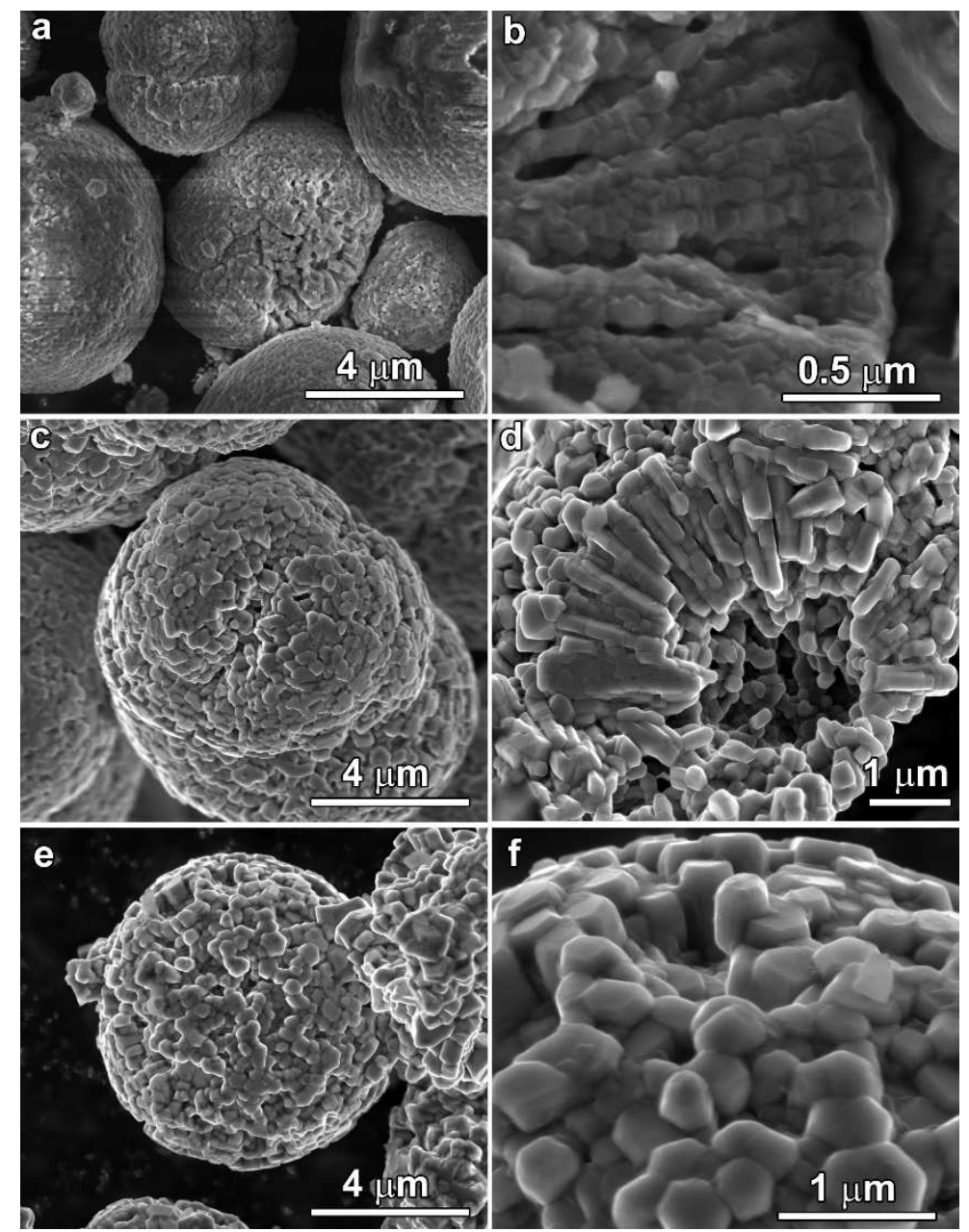

Fig. 7 : SEM images providing close-up view at the spherical agglomerates in the $L i / M=1.35(a, b), L i / M=$ $1.5(\mathrm{c}, \mathrm{d})$ and $\mathrm{Li} / \mathrm{M}=1.8(\mathrm{e}, \mathrm{f})$ samples.

Another striking difference between the microstructure of the spherical agglomerates in the low Li/M $(1.2,1.35)$ and high Li/M $(1.5,1.65,1.8)$ samples is revealed by high resolution HAADFSTEM imaging. In the $\mathrm{Li} / \mathrm{M}=1.35$ sample (Fig. 8 , top) the $c$-axis of the monoclinic $C 2 / m$ structure within the nano crystallites is oriented tangential to the curvature of the spherical agglomerate, so that the $\mathrm{LiM}_{2}$ layers adopt the radial orientation providing the easy Li diffusion direction from the center of the sphere towards its surface. Contrarily to that, in the Li/M=1.5 sample (Fig. 8 , bottom) the $c$-axis is oriented along the rod-like crystals, so that the $\mathrm{LiM}_{2}$ layers are always tangential to the surface of the spheres. This might obstacle the $\mathrm{Li}$ diffusion as the shortest way for the $\mathrm{Li}^{+}$ions to leave the agglomerates is to travel across the $\mathrm{LiM}_{2}$ layers. 

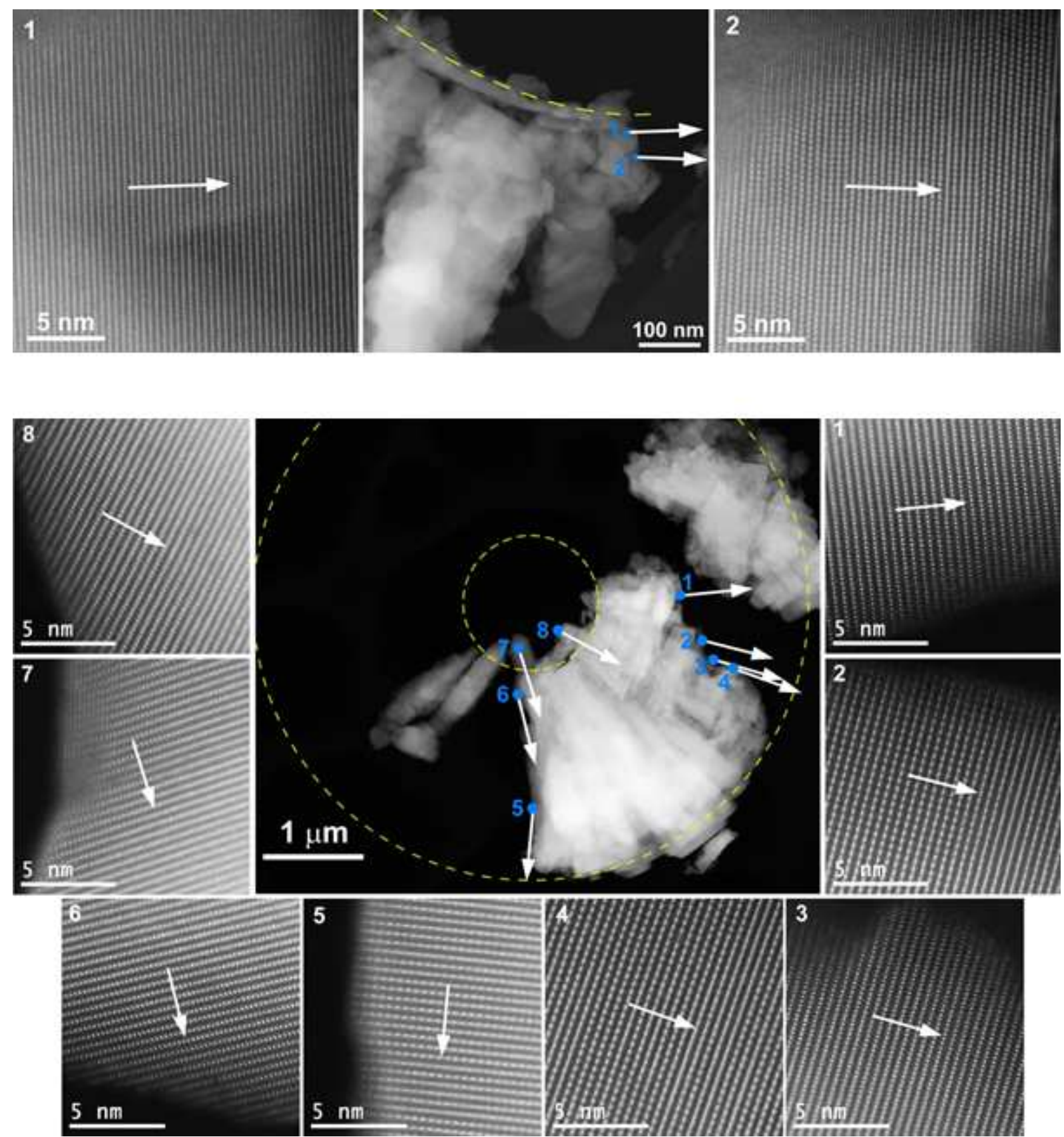

Fig. 8 : Low magnification HAADF-STEM image of a fractured spherical agglomerate and high resolution HAADF-STEM images of constituting crystallites showing orientation of the $\mathrm{LiM}_{2}$ layers and the $c$-axis (pointed by arrows). Yellow circles mark the agglomerate curvature before fracturing. Numbers on the high resolution HAADF-STEM images correspond to the positions marked on the low magnification HAADFSTEM image. Top panel - the $\mathrm{Li} / \mathrm{M}=1.35$ sample, bottom panel - the $\mathrm{Li} / \mathrm{M}=1.5$ sample.

\section{Electrochemical studies}

Galvanostatic charge-discharge measurements were performed for both 0.1 mol. $\mathrm{L}^{-1}$ and 0.4 mol. $\mathrm{L}^{-1}$ series of samples at $0.1 \mathrm{C}$ rate between $4.8-2 \mathrm{~V}$ (Fig. 9 left). The latter are solely discussed 
owing to their similarities with the former. Several interesting features can be spotted. There is a drastic evolution of the first charging voltage profile upon increasing the Li/M ratio with namely the presence of the high voltage plateau associated to the anionic redox process in Li-rich NMC for 1.2 $<\mathrm{Li} / \mathrm{M}<1.5$ and its effective disappearance for $\mathrm{Li} / \mathrm{M}>1.5$. Turning to the discharge process, the sample with $\mathrm{Li} / \mathrm{M}=1.2$ shows a first discharge capacity of about $250 \mathrm{mAh} . \mathrm{g}^{-1}$ which decays to $\sim 200$ mAh.g ${ }^{-1}$ after 100 cycles and whose voltage equally decreases by $\sim 500 \mathrm{mV}$ over the same cycling range. While keeping nearly the same cycling and voltage decays, the $\mathrm{Li} / \mathrm{M}=1.35$ sample shows the largest capacity of the series approaching nearly $270 \mathrm{mAh} \cdot \mathrm{g}^{-1}$. Increasing further the $\mathrm{Li} / \mathrm{M}$ ratio to 1.5 results in a severe decrease of the first discharge capacity to $\sim 170 \mathrm{mAh} . \mathrm{g}^{-1}$ which therefore progressively increases afterwards upon cycling prior to stabilize at $~ 200 \mathrm{mAh} . \mathrm{g}^{-1}$ after 50 cycles. This unusual trend of increase in capacity with cycling is even more pronounced for the samples with $\mathrm{Li} / \mathrm{M}=1.65$ and 1.8 , that show respectively $\sim 60$ and $\sim 20 \mathrm{mAh} \cdot \mathrm{g}^{-1}$ in the first discharge, but reach the values exceeding $200 \mathrm{mAh} . \mathrm{g}^{-1}$ after 50 cycles. Such an effect which goes hand in hand with the disappearance of the upper voltage charging plateau is reminiscent of the onset of kinetic limitations within the electrode upon increasing Li/M.

Extra features can be observed in the derivative curves (Fig. 9 right) with namely the presence of a peak at $3 \mathrm{~V}$ in the cathodic scan for the $\mathrm{Li} / \mathrm{M}=1.2$ sample confirming the presence of a spinel impurity, as already observed on the XRD pattern. This peak grows considerably upon cycling while shifting to lower potential $(\sim 2.8 \mathrm{~V})$ as also observed for $\mathrm{Li} / \mathrm{M}=1.35$ for which most of the discharge capacity becomes centered at low voltage suggesting the cycling-driven formation of a spinel-like phase. Moreover, note that for both samples the voltage decay rate is faster over the first twenty cycles than that on subsequent cycles, with nearly no voltage fade beyond 50 cycles (Fig. S7). A different behavior is observed for the samples with higher $\mathrm{Li} / \mathrm{M}$ as there is no appearance of a well pronounced peak at $2.8 \mathrm{~V}$ but rather a shoulder that solely grows once the samples have reached their optimum capacity beyond 50 cycles. Moreover, there is no drastic shift of the redox peaks (e.g, no voltage fade) during the initial tenths of cycles as the maximum capacity (e.g full anionic redox activity) has not been fully reached, indirectly suggesting that the voltage fade is linked to the anionic redox activity. 

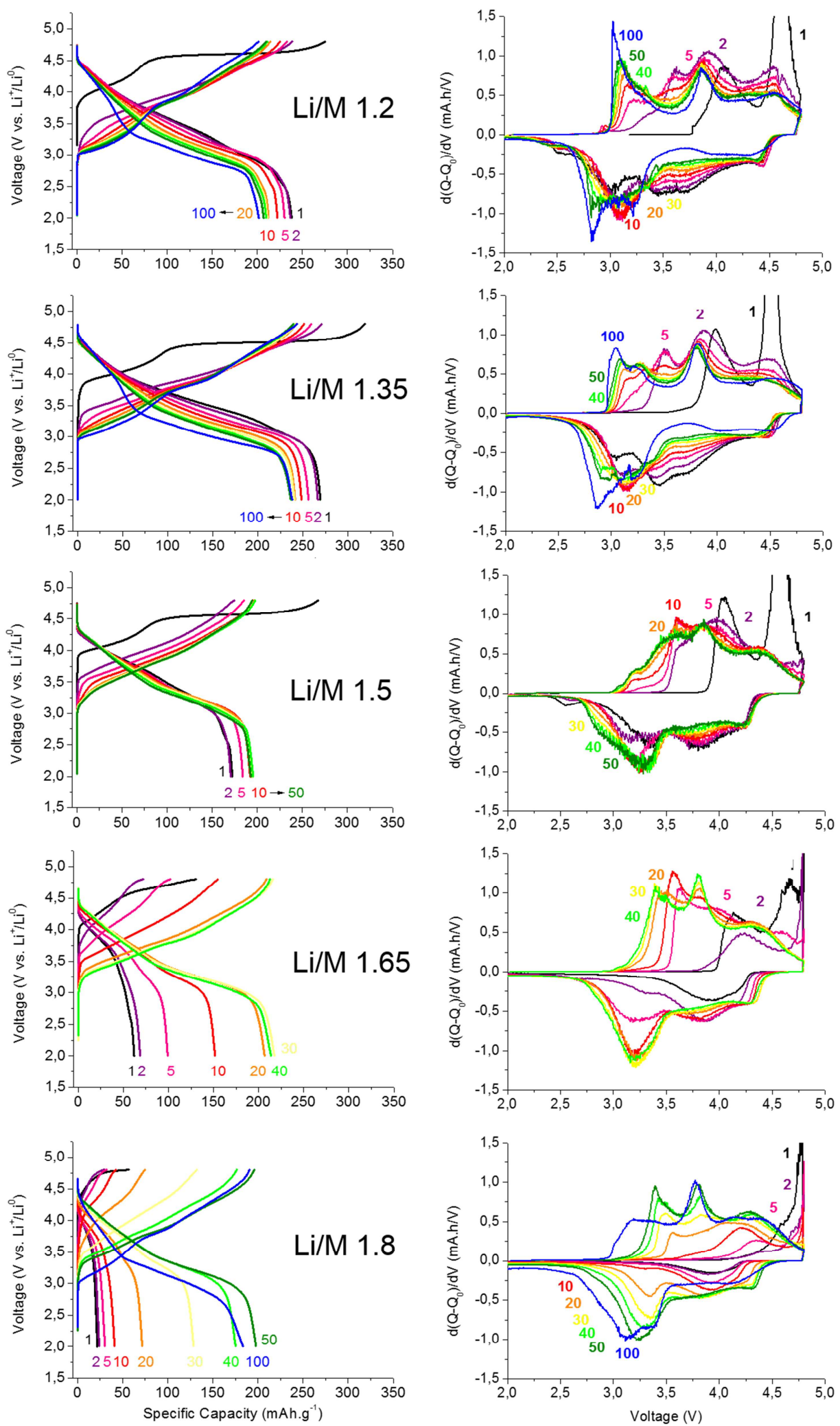

Fig. 9 : Galvanostatic charge-discharge curves of Li-rich NMC synthesized with different Li/M ratio (left) and respective $\mathrm{dQ} / \mathrm{dV}$ plots (right).

Figure 10 compares the performance of the samples with different $\mathrm{Li} / \mathrm{M}$ ratio as a function of number of cycles. Note that the number of activation cycles increases with the Li/M ratio. 
Therefore, once the activation period is finished, they all show good capacity retention with the values ranging from $200 \mathrm{mAh} \cdot \mathrm{g}^{-1}$ to $250 \mathrm{mAh} \cdot \mathrm{g}^{-1}$. For sake of completion, similar galvanostatic tests were performed for the $0.1 \mathrm{~mol} . \mathrm{L}^{-1}$ series of samples, which for specific compositions were showing slightly different spherical particles size or morphologies (compact vs. hollow-like particles). The results shown in Fig. 10b are nearly alike those of Fig. 10a indicating that our synthesis protocol can be scaled up without major surprises.
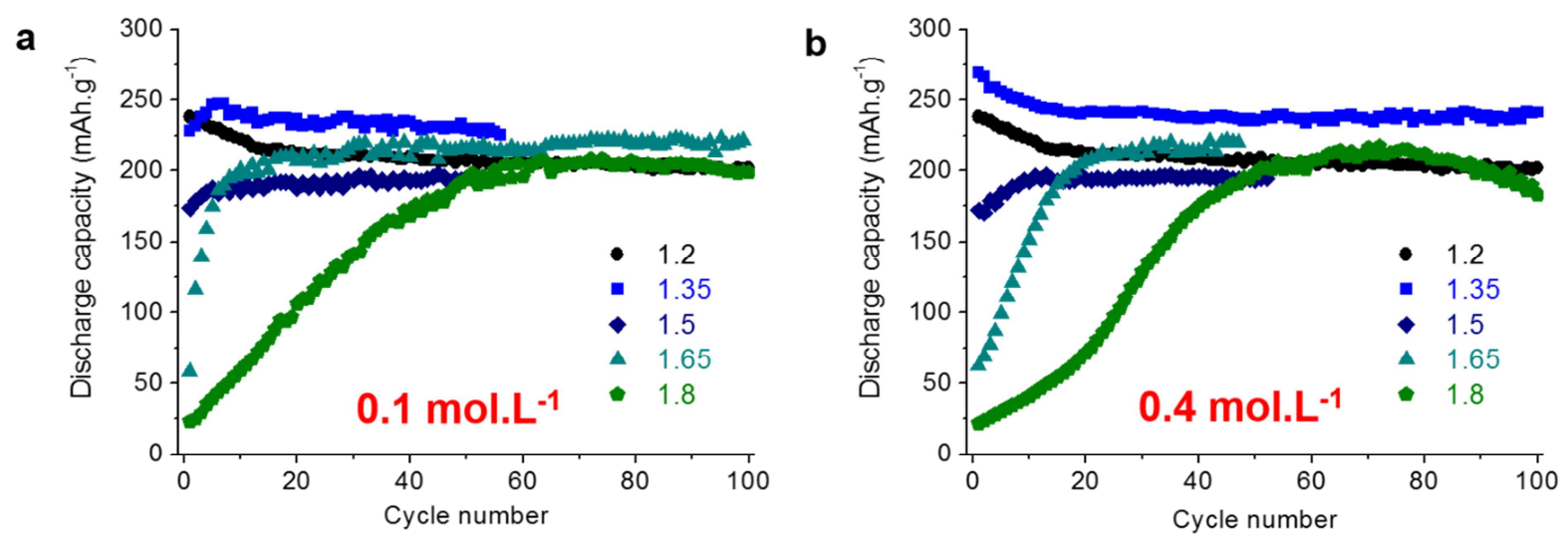

Fig. 10 : Capacity retention curves of Li-rich NMC synthetized with different Li/M at two concentrations, 0.1 mol. $\mathrm{L}^{-1}(\mathrm{a})$ and $0.4 \mathrm{~mol} \cdot \mathrm{L}^{-1}(\mathrm{~b})$.

Worth emphasizing here is that the evolution of the cathodic (reduction) peak at $2.8 \mathrm{~V}$ during cycling, frequently referred as the spinel-like phase, differs from true spinel structure as the growth of this peak at $2.8 \mathrm{~V}$ is not associated with growing anodic peak at $4.1 \mathrm{~V}$ as expected for spinel materials such as $\mathrm{LiMn}_{2} \mathrm{O}_{4}$. Whatever, to throw some light onto this issue we decided to investigate, via high resolution electron microscopy, the local structure evolution in Li-rich NMC electrodes ( $\mathrm{Li} / \mathrm{M}=1.35)$ at different stages of the electrochemical cycling. We focus on the pristine, $2^{\text {nd }}$ and $100^{\text {th }}$ cycled samples discharged to $2 \mathrm{~V}$. Our choice for looking at an electrode cycled only twice lies in the strong change in capacity of our electrodes at the early cycling stage.

The ED patterns of the pristine material demonstrate bright spots characteristic of the $\mathrm{O} 3$ structure (Fig. 11a). Within the electron diffraction precision, these reflections can be indexed with $R \overline{3} m$ unit cell with $a \approx 2.9 \AA, c \approx 14.2 \AA$. Sharp diffuse intensity lines are clearly visible in the [ $\overline{1} 10]$ ED pattern (Fig. 11b) that indicates 2D honeycomb ordering of the $\mathrm{Li}$ and $\mathrm{M}$ cations within the $\mathrm{LiM}_{2}$ 
layers, but the periodicity of this ordering along the stacking direction is violated by numerous stacking faults. A perfect $\mathrm{O} 3$ structure is evident from the [010] HAADF-STEM image (Fig. 11 bottom). The [1]10] HAADF-STEM image demonstrates honeycomb ordering of the $\mathrm{Li}$ and $\mathrm{M}$ cations. In this projection it manifests itself as pairs of prominently bright dots separated by $\sim 0.14$ $\mathrm{nm}$ corresponding to the $\mathrm{M}$ columns, alternating with the dark spacers corresponding to the Li-rich columns. Stacking faults in the honeycomb ordering are visible by lateral displacements of the layers, as traced by a zig-zag line in Fig. 11c. Occasionally, the defect $\mathrm{Li}_{1-x} \mathrm{M}_{2+\mathrm{x}}$ layers have been observed, where the ordering of the Li and M atoms is partially or completely suppressed (marked with arrowheads in Fig. 11d). Antisite defects (i.e. Li/M exchange between the $\mathrm{Li}_{3}$ and $\mathrm{LiM}_{2}$ layers) are not observed in the bulk of the crystallites.

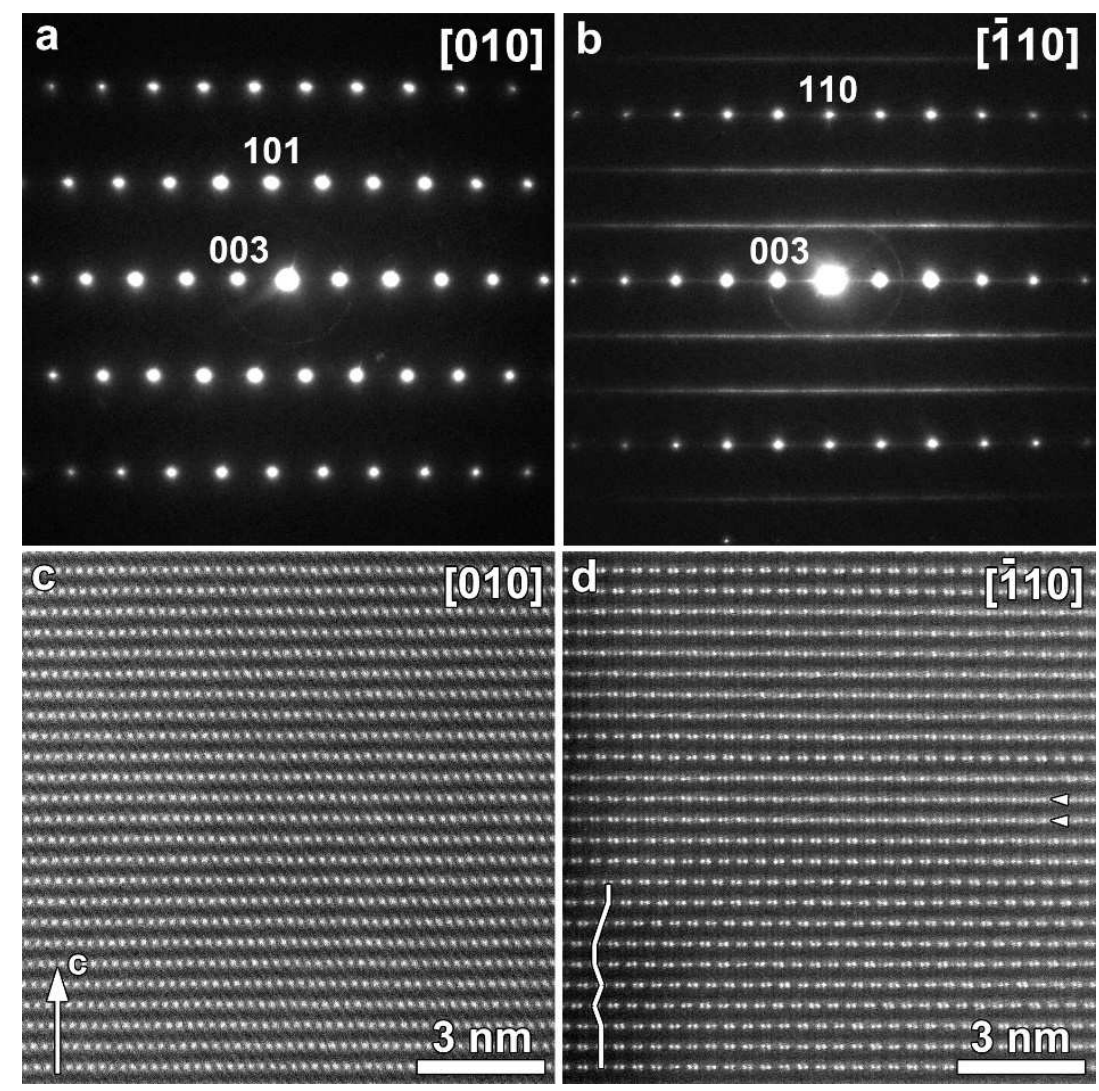

Fig. 11: [010] (a) and [1110] (b) ED patterns of the pristine Li/M=1.35 material (indexed in the trigonal basic cell of the $\mathrm{O} 3$ structure) and the corresponding [010] (c) and [1]10] (d) HAADF-STEM images. The periodicity along the stacking direction of the "honeycomb" layers is violated by numerous stacking faults visible as lateral shifts of the $\mathrm{LiM}_{2}$ layers (traced with the white line). Some disordered $\mathrm{LiM}_{2}$ layers are marked with arrowheads. 
The ED patterns for the material cycled two times (Fig. S8) demonstrate a close resemblance to the ED patterns of the pristine phase. The [010] ED pattern, however, shows very weak superlattice reflections at the $h \pm 1 / 2,0, \pm 1$ positions. According to the analysis of the [010] ABF-STEM images, these reflections manifest a formation of the seeds of spinel-like structure (Fig. 12). In the ABF image the intensity is roughly proportional to the cubic root of the average atomic number along the atomic column that allows observation of oxygen and even Li columns. In Fig. 12 , the darkest dots correspond to the cationic columns of the $\mathrm{Li}_{1-x} \mathrm{M}_{2+x}$ layers. The rows of these dark dots are sandwiched by two rows of fainter dots of the oxygen columns forming the octahedral environment of the $\mathrm{M}$ and $\mathrm{Li}$ cations (traced in the enlargement 2 of Fig. 12). Rows of faint dots right in the middle between the $\mathrm{Li}_{1-x} \mathrm{M}_{2+x}$ layers are the $\mathrm{Li}_{3}$ layers. The crystal surface is confined to the $\{10 \overline{2}\}$ lattice plane (marked with the dashed line in Fig. 12). Within the surface layer the antisite $\mathrm{Li} / \mathrm{M}$ disorder is clearly seen by increased darkness of the dots in the $\mathrm{Li}_{3}$ layers compared to the one in the bulk. The outlined region 1 shows a split cationic position in the $\mathrm{Li}_{3}$ layer which apparently indicates a displacement of the $\mathrm{Li}$ cations from the octahedral position to the neighboring tetrahedral interstices. The outlined region 2 demonstrates a line defect which is a nucleation of the $\{10 \overline{2}\}$-oriented $\mathrm{M}$-cation layer in the matrix of the $\{001\}$-oriented $\mathrm{Li}_{1-\mathrm{x}} \mathrm{M}_{2+\mathrm{x}}$ layers. The dots of the $\mathrm{M}$ columns in the $\mathrm{Li}_{1-\mathrm{x}} \mathrm{M}_{2+x}$ layers next to the defect appear to be quite shallow indicating a migration of the $\mathrm{M}$ cations to the octahedral positions in the $\mathrm{Li}_{3}$ layer above and below that creates a short fragment of the $\{10 \overline{2}\}$-oriented layer in the matrix of the $\{001\}$-oriented layers. One should note that the $\{001\}$ and $\{10 \overline{2}\}$ in the $\bigcirc 3 R \overline{3} m$ structure are, in fact, $\{111\}$ close-packed planes of the $f c c$ lattice characteristic of a spinel structure. A formation of multiple system of the close-packed $\{111\}$ planes with the octahedral interstices populated by the $M$ cation manifests a nucleation of the spinel phase in the matrix of the layered $\mathrm{O} 3$ structure. Point defects with the $\mathrm{Li}$ atoms migrated to the tetrahedral interstices support this consideration. Although these defects occur in this sample only occasionally, they indicate that the layered-to-spinel transformation is initiated already after two charge-discharge cycles. Super lattice reflections in the ED patterns demonstrate that the concentration of the fragments of the $\{10 \overline{2}\}$-oriented cation layers is already sufficient to segregate and form local ordering. 


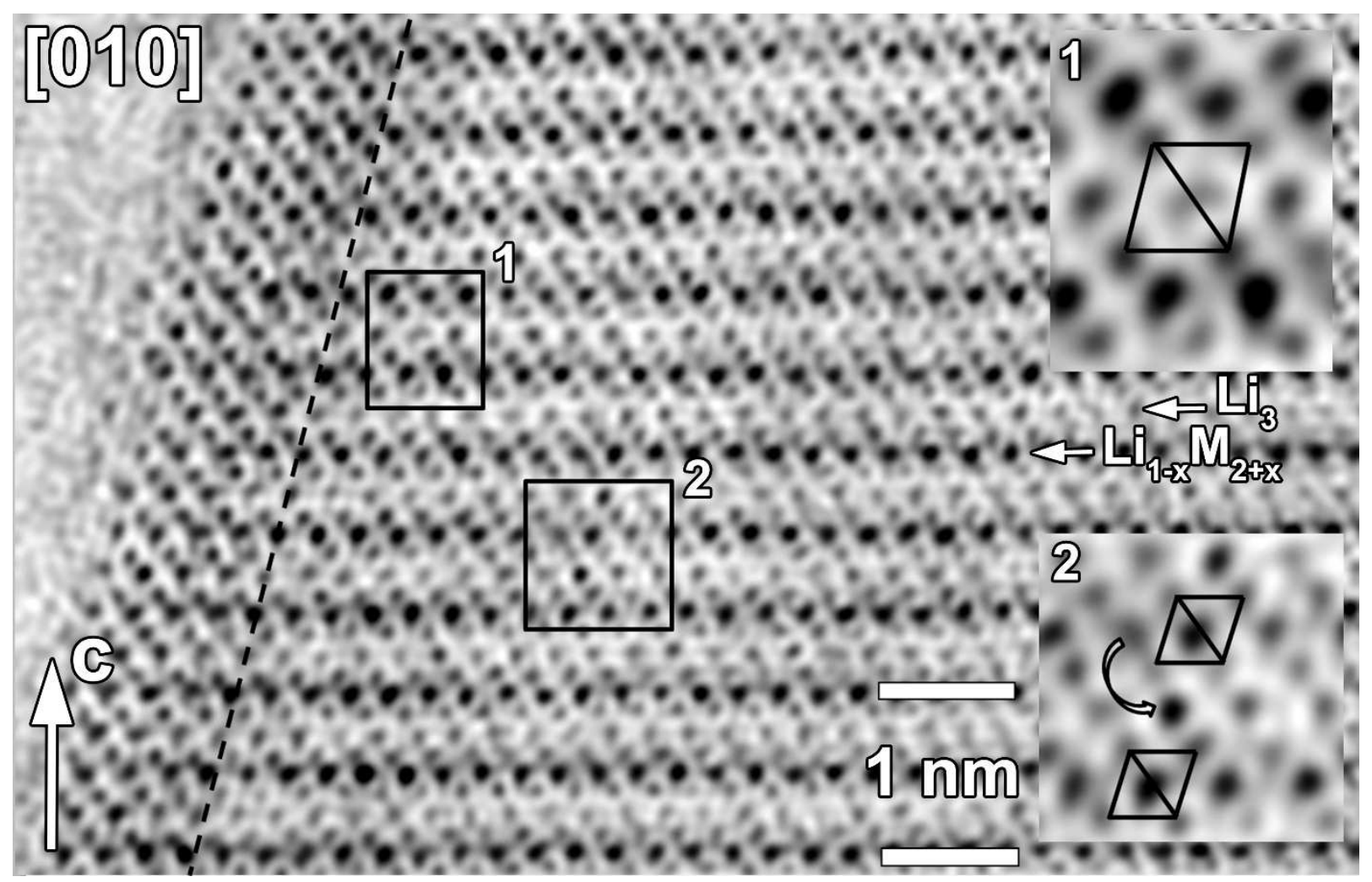

Fig. 12 : [010] ABF-STEM image of the $\mathrm{Li}_{1.2} \mathrm{Ni}_{0.13} \mathrm{Mn}_{0.54} \mathrm{Co}_{0.13} \mathrm{O}_{2}$ material discharged to $2 \mathrm{~V}$. Dashed line marks the near-surface layer with pronounced Li/M antisite disorder. The region 1 shows point defect where

the cations are located at the tetrahedral voids (outlined in the enlargement 1) instead of the regular octahedral position. The area 2 demonstrates a line defect which is a nucleation of the $\{10 \overline{2}\}$-oriented M-

based layer in the matrix of the $\{001\}$-oriented $\mathrm{Li}_{1-x} \mathrm{M}_{2+x}$ layers. The enlargement 2 shows a migration direction of the $\mathrm{M}$ cation from the $\{001\}$-oriented $\mathrm{Li}_{1-x} \mathrm{M}_{2+x}$ layer toward the adjacent octahedral position in the $\{10 \overline{2}\}$-oriented layer. Oxygen octahedra around the $M$ cations in the $L_{1-x} M_{2+x}$ layers are outlined.

In the ED patterns of the material cycled 100 times, the brightest spots still belong to the parent $\mathrm{O} 3$ layered structure (Fig. 13 a,b). However, the regular $h \pm 1 / 2,0,4 \pm 1$ and $h \pm 1 / 2, k \pm 1 / 2, I$ super lattice reflections are seen in the [010] and [110] ED patterns, respectively. These reflections originate from greatly increased fraction of the ordered $\{10 \overline{2}\}$-oriented M-cation layers. Geometrically, these super lattice reflections correspond to a spinel-type tetragonal structure with a $\approx 5.7 \AA, c \approx 9.3 \AA$ and $14_{1} /$ amd space group. The [010] HAADF-STEM image indeed reveals migration of the $\mathrm{M}$ cations to the octahedral positions in the $\mathrm{Li}_{3}$ layers and their preferential alignment along the $\{10 \overline{2}\}$ lattice planes (Fig. 13c, arrowheads). [110] HAADF-STEM image also 
shows that a large fraction of the $M$ cations now replaces $\mathrm{Li}$ in the $\mathrm{Li}_{3}$ layers (Fig. 13d). The "honeycomb" ordering in the $\mathrm{LiM}_{2}$ layers (as recognized by pairs of $0.14 \mathrm{~nm}$-separated bright dots in Fig. 13d) is now absent: the dots in these layers are uniformly spaced and have similar brightness that indicates complete intermixing of the $\mathrm{Li}$ and $\mathrm{M}$ cations.

To conclude the atomic resolution TEM analysis we would like to explicitly specify the term "spinel" in the context of the structure evolution of the $\mathrm{Li}_{1.2} \mathrm{Ni}_{0.13} \mathrm{Mn}_{0.54} \mathrm{Co}_{0.13} \mathrm{O}_{2}$ phase with the number of charge-discharge cycles. We should stress that even after 100 cycles we did not observe a formation of spinel as a separate bulk phase or even domains with the extension of more than $20 \mathrm{~nm}$. The actual state of the discharged sample is better described as a highly defective layered structure with large degree of the Li/M intermixing and local spinel-like Li/M ordering in a form of nano domains. This vision fully agrees with the earlier TEM investigations on the cycled $\mathrm{Li}_{1.2} \mathrm{Ni}_{0.13} \mathrm{Mn}_{0.54} \mathrm{Co}_{0.13} \mathrm{O}_{2}$ material. ${ }^{46,47}$

On a larger spatial scale the images demonstrate a formation of numerous pits and cracks. Low magnification HAADF-STEM images show numerous nm-sized dark spots (e.g, pits) over the NMC crystals (Fig. S9) due to material loss, which undeniably must affect capacity fade. Moreover, the rod-like crystallites contain numerous cracks along the $\{001\}$ planes of the layered structure (Fig. S10a); the spherical agglomerates appear to be cracked too being split into several parts (Fig. S10b). Simultaneous presence of these two systems of cracks suggests that the crystallites are subjected mostly to radial tensile strain during cycling, whereas on the scale of whole agglomerate a tangential tensile strain prevails. We believe that the observed capacity fade after long cycling is mainly due to primary and secondary particles cracking in agreement with previous reports. ${ }^{48,49}$

Overall, electron microscopy results indicate that upon cycling the material suffers from Li/M intersite mixing with a formation of spinel-like nanodomains. The key finding is that once such a high degree of disorder has been reached, there is no any longer voltage fades and only very limited capacity fade. Practically-wise it is therefore unfortunate that such a layered/spinel-like mixed state is associated to a large voltage drop which penalizes the overall energy density of the material. 


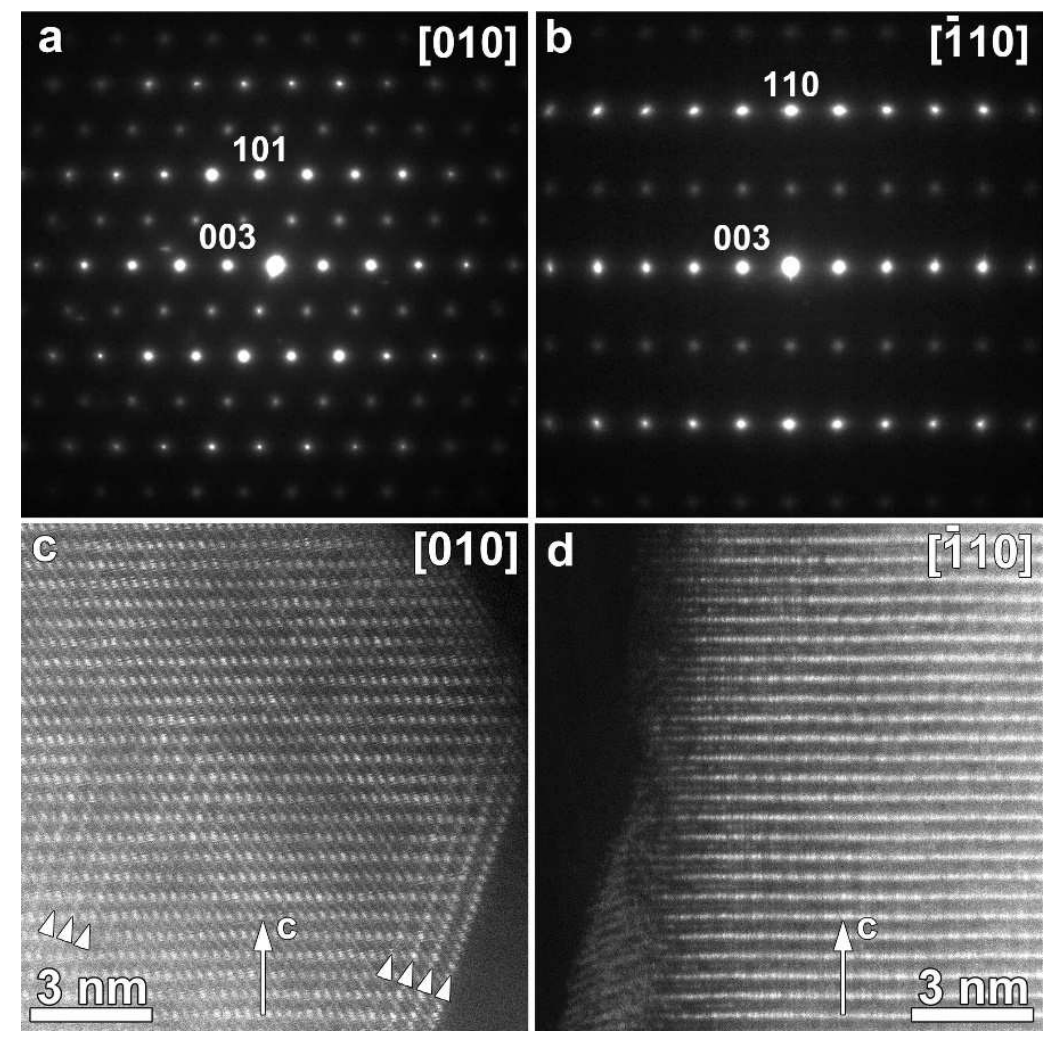

Fig. $13:[010]$ (a) and [110] (b) ED patterns of the $L \mathrm{i} / \mathrm{M}=1.35$ material cycled 100 times (indexed in the trigonal basic cell of the $\mathrm{O} 3$ structure) and the corresponding [010] (c) and [1110] (d) HAADF-STEM images (to be compared with the images of the pristine material in Fig. 11). The newly created $\{10 \overline{2}\} \mathrm{M}$-cation planes are marked with arrowheads.

At this stage a legitimate question deals with the origin of the capacity increase upon cycling for the $\mathrm{Li} / \mathrm{M}>1.35$ samples. It is worth recalling that such an effect is not new, as it was already reported in several studies on Li-rich NMC materials, but no consensus on its origin was reached. Some authors ascribed such an effect to the amount of Co within the Li-rich NMC phase as they observed shortening of the number of activation cycles with increasing the amount of Co. ${ }^{50}$ Others specified that the capacity increase is linked to the progressively growing redox-reaction of $\mathrm{Mn}$ which can be avoided by enhancing the charge cut-off potential or lowering the charging current suggesting a kinetic limitation. Lastly, the activation of the $\mathrm{Li}_{2} \mathrm{MnO}_{3}$ moiety ${ }^{51}$ is also pushed forward as the origin of this capacity increase stating in some cases that the gradual increase in capacity is associated with the structure transformation from layered to spinel phase. Some of these propositions can be ruled out as we presently observed this effect without modifying the overall Co content or without having domains of $\mathrm{Li}_{2} \mathrm{MnO}_{3}$ in our samples which were solid solutions at the 
nanoscale as deduced by HR-STEM. The layered to spinel transformation does not hold either since we evidence such a transformation for the $\mathrm{Li} / \mathrm{M}=1.2$ and 1.35 samples as well. In other hand our results tend to favor the kinetic limitation argument, hence our desire to further explore the $\mathrm{Li} / \mathrm{M}=1.8$ sample which shows the largest activation process ( $\sim 50$ cycles).

We check the effect of current density by lowering the cycling currents from $\mathrm{C} / 10$ to $\mathrm{C} / 30$ (Fig. 14). The decline in the current density leads to a drastic shortening of the activation cycles to reach a steady capacity of $225 \mathrm{mAh} \cdot \mathrm{g}^{-1}$ and this goes hand in hand with an increase of the high voltage plateau, hence confirming kinetic limitations and highlighting the importance of triggering the anionic redox activity. Cycling-driven electrochemical activation is usually the result of an electrochemical grinding process that reduces the particle size to enhance their reactivity or breaks film deposits around particles that could block Li-ion transport.
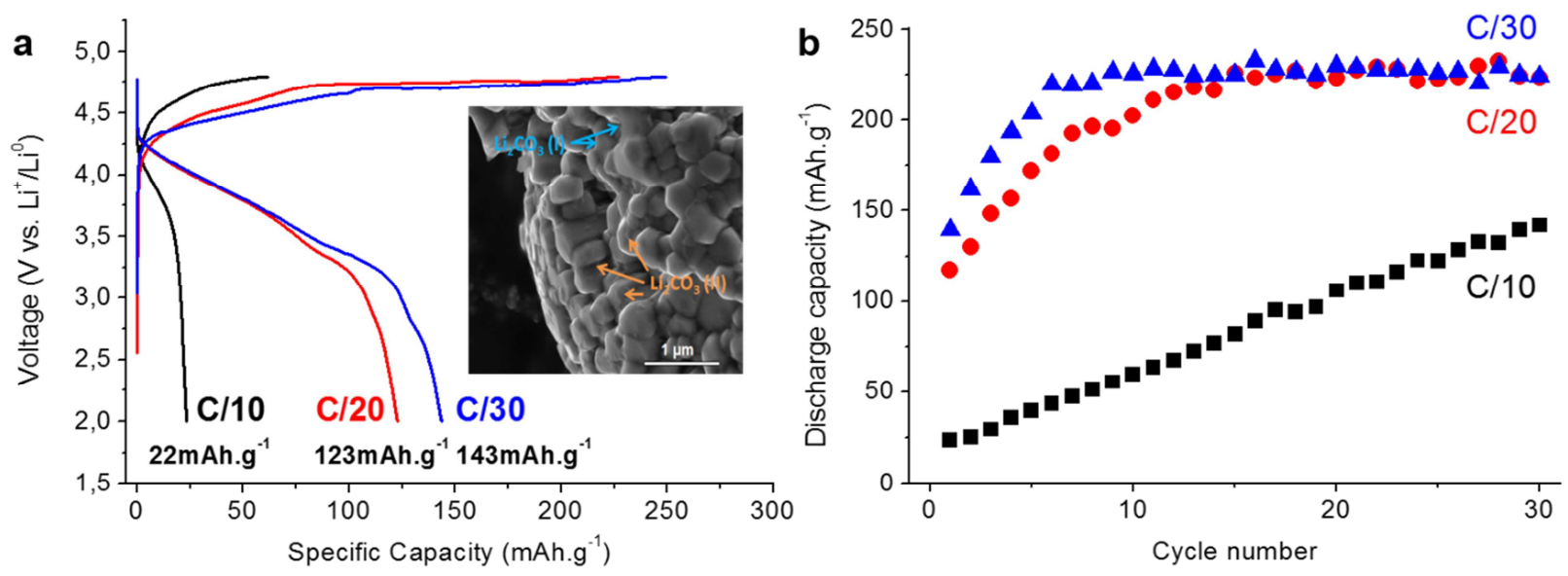

Fig. 14 : Galvanostatic charge-discharge profiles the $\mathrm{Li} / \mathrm{M}=1.8$ sample at different $\mathrm{C}$ rates (a); capacity retention plots at different $\mathrm{C}$ rates $(\mathrm{b})$.

Within this context we should recall that the particles in our $\mathrm{Li} / \mathrm{M}=1.8$ sample are coated by a surface layer of $\mathrm{Li}_{2} \mathrm{CO}_{3}$ as deduced by the glassy deposit around the faceted crystals (SEM microscopy insert in Fig. 14a) and confirmed by XRD (Fig. 5, top right). Thus, to eliminate the $\mathrm{Li}_{2} \mathrm{CO}_{3}$ coating, the sample was heavily washed with cold water, dried and electrochemically tested at a $\mathrm{C} / 10$ rate. This washing step enhances drastically the capacity from 45 to $105 \mathrm{mAh} . \mathrm{g}^{-1}$ (Fig. 15a) with an even greater increase to $130 \mathrm{mAh} \cdot \mathrm{g}^{-1}$ being achieved when the sample was ball milled for $1 \mathrm{~h}$ with a ball to material weight ratio of 40 . This increase implies a better access to the 
sample core that is made feasible by the ball milling step which both fractures the $\mathrm{Li}_{2} \mathrm{CO}_{3}$ coating and reduces the particle size. Within this context of particle size it is worth mentioning that the increase in crystallinity of the materials with the $\mathrm{Li} / \mathrm{M}$ ratio is due to the increasing excess of $\mathrm{Li}_{2} \mathrm{CO}_{3}$ which acts as a crystallization flux and enhances the size of primary particles and their orientation, hence affecting the electrode kinetics as well. In line with this kinetic limitation hypothesis is our ability to improve the discharge capacity of our unwashed electrode to $205 \mathrm{mAh} . \mathrm{g}^{-1}$ by raising its cycling temperature to $55^{\circ} \mathrm{C}$ (Fig. 15b).
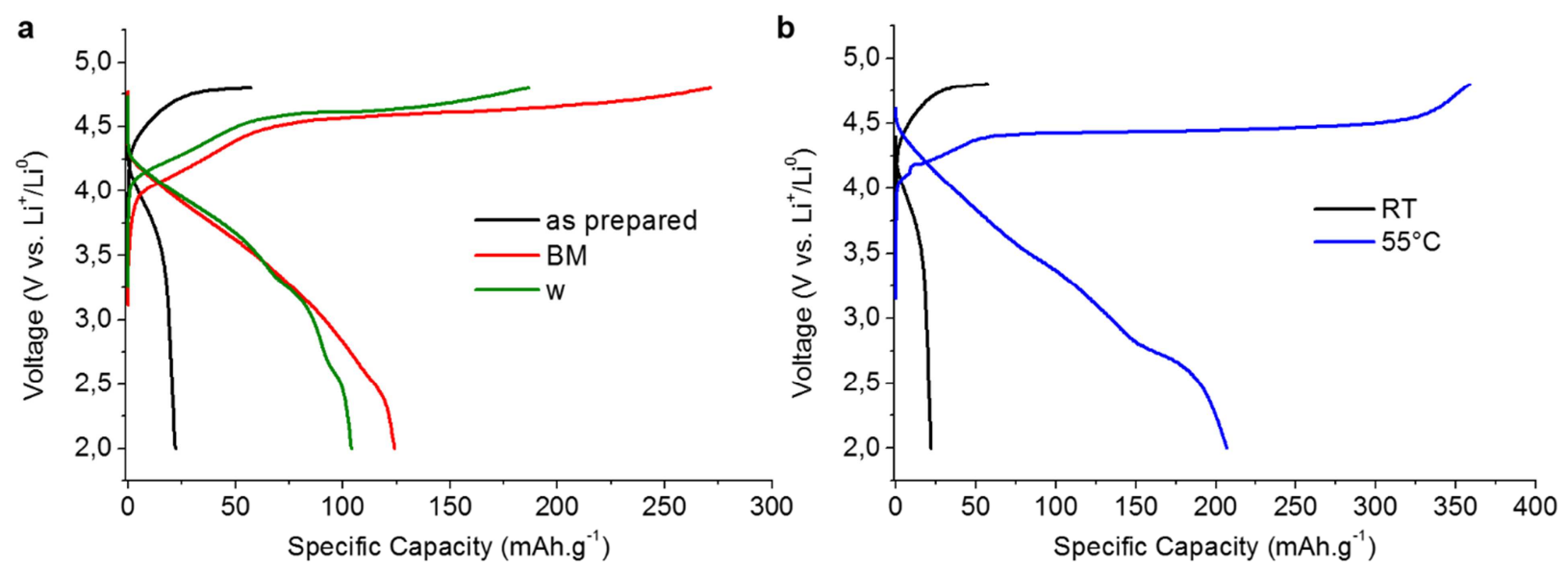

Fig. 15 : Galvanostatic charge-discharge profile (4.8-2V at $C / 10)$ of the $L i / M=1.8$ sample after washing and ball-milling (a); charge-discharge profile $(4.8-2 \mathrm{~V}$ at $\mathrm{C} / 10)$ at $55^{\circ} \mathrm{C}(\mathrm{b})$.

We further explore the impact of increasing the temperature from $25^{\circ} \mathrm{C}$ to $40^{\circ} \mathrm{C}$ and $55^{\circ} \mathrm{C}$ on both the capacity and cycling performance of the $\mathrm{Li} / \mathrm{M}=1.35$ sample and note an increase in capacity (Fig. 16a) by $16 \%$ while preserving the capacity retention which is about $97 \%$ and $95 \%$ at 40 and $55^{\circ} \mathrm{C}$, respectively (Fig. 16b). Such an increase in capacity is nested in a better activation of the anionic redox activity that occurs through the $4.5 \mathrm{~V}$ voltage plateau. This is further indicative of the sluggish kinetics of the anionic redox process previously reported. ${ }^{52,53}$ Lastly, besides the carbonates coating, the worse kinetic of the $\mathrm{Li} / \mathrm{M}>1.5$ samples as compared to that of the $\mathrm{Li} / \mathrm{M}<$ 1.5 samples, can also be nested in the different texture between the materials as revealed by HRSTEM which has shown that the nano crystallites are oriented in a way that $\mathrm{LiM}_{2}$ layers adopt the tangential $(\mathrm{Li} / \mathrm{M}>1.5)$ rather than the radial orientation $(\mathrm{Li} / \mathrm{M}<1.5)$, with the latter being better for ionic conduction. 

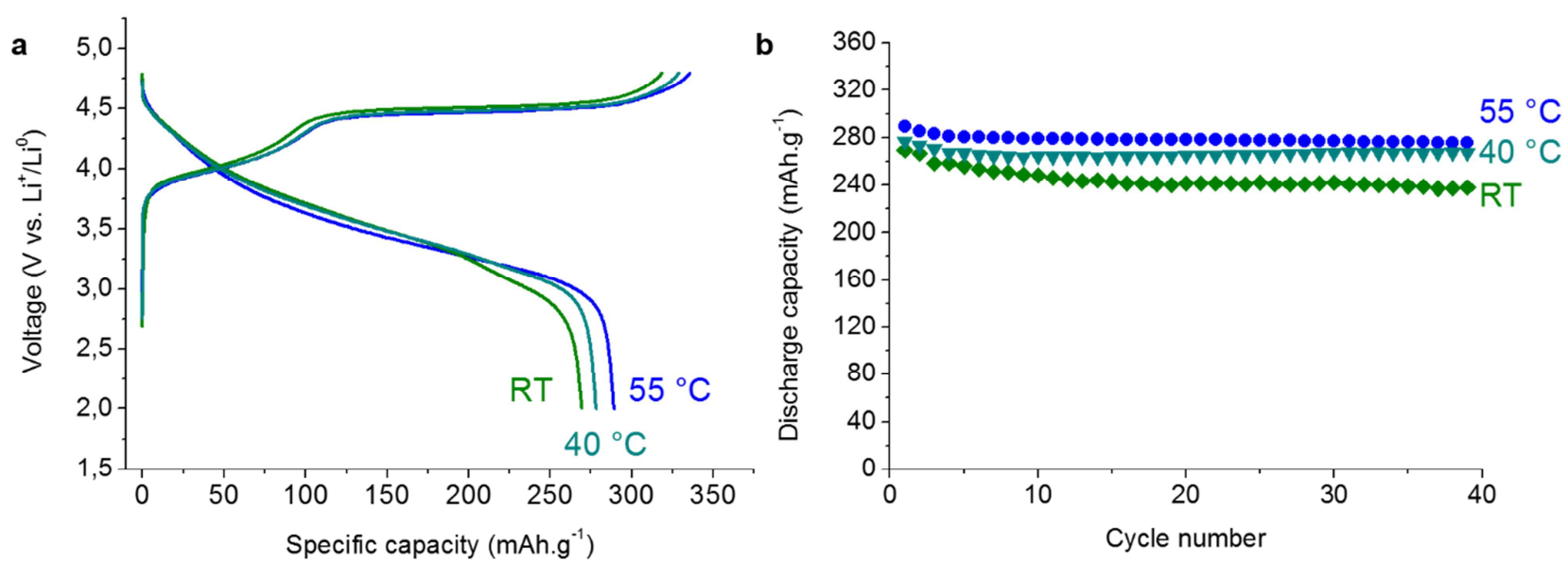

Fig. 16 : Galvanostatic charge-discharge curves of Li-rich NMC Li/M=1.35 at different temperatures rates (a); Capacity retention plot of Li/M 1.35 vs $\mathrm{T}$ (b).

\section{Conclusion}

We have reported the importance of precursor synthesis and the impact of $\mathrm{Li} / \mathrm{M}$ ratio on the electrochemical properties of Li-rich layered NMC compounds. By following the kinetics of the precipitation mechanism, we have shown that the mixed Ni-Mn-Co carbonate precipitation is a complex and delicate process which needs a strict control of all parameters, such as $\mathrm{pH}$, feeding rate, temperature and stirring. We shed light on the hierarchical assembly of micro/nano-sized spherical particles that are formed by two distinct mechanisms: oriented aggregation followed by Ostwald ripening. Based on this understanding we demonstrate the feasibility to obtain NMC carbonate particles with different sizes, ranging from 5 to $10 \mu \mathrm{m}$, by solely changing the concentration of the precipitation solution from $0.1 \mathrm{~mol} . \mathrm{L}^{-1}$ to $0.4 \mathrm{~mol} . \mathrm{L}^{-1}$, respectively.

These tailor-made carbonate precursors have been used to conduct a comprehensive study on the effect of the $\mathrm{Li} / \mathrm{M}$ ratio in the $\mathrm{Li}_{2} \mathrm{CO}_{3} / \mathrm{NMC}$ carbonate mixture on the electrochemical behaviour of the $\mathrm{Li}_{1.2} \mathrm{Ni}_{0.13} \mathrm{Mn}_{0.54} \mathrm{Co}_{0.13} \mathrm{O}_{2}$ material. The best electrochemical performance was achieved for the composition $\mathrm{Li} / \mathrm{M}=1.35$ which shows a capacity of 240 and $270 \mathrm{mAh} \cdot \mathrm{g}^{-1}$ at RT and $55^{\circ} \mathrm{C}$ with a capacity retention of $90 \%$ after 100 cycles. Therefore two different domains were unravelled performance-wise with capacity decay upon cycling for $1.2 \leq \mathrm{Li} / \mathrm{M} \leq 1.35$ samples as opposed to an unusual capacity increase for $1.5 \leq \mathrm{Li} / \mathrm{M} \leq 1.8$. 
From electrochemical tests we could deduce that increase in capacity upon cycling was rooted in kinetic limitations associated to specific morphological changes of the spherical particles with increasing $\mathrm{Li} / \mathrm{M}$ as visualized by electron microscopy. Increasing the amount of $\mathrm{Li}_{2} \mathrm{CO}_{3}$ was shown to preserve the overall particles sphericity together with the coaxial assembly of crystallites rods with therefore a coarsening of the rods due to the increasing amount of $\mathrm{Li}_{2} \mathrm{CO}_{3}$ flux which favours crystallization. This must obstacle the $\mathrm{Li}^{+}$diffusion. Therefore the major limitation is the increasing amount of blocking $\mathrm{Li}_{2} \mathrm{CO}_{3}$ deposits around the particles that prevents to access the full material capacity till this coating can be fully ruptured by electrochemical grinding via continuous cycling. Interestingly, we note that a more efficient activation by lowering the cycling current so that we could have access to the $4.2 \mathrm{~V}$ plateau associated both to the anionic redox activity and $\mathrm{Li}_{2} \mathrm{CO}_{3}$ removal.

Practically-wise we show that the preparation of precursors on the scale of a dozen or even 50 gram did not have any effect on the electrochemical performances of the resulting NMC as long as the Li/M amount was properly adjusted to limit the coarsening of the primary rod-like particles. On that basis, one can expect the overall protocol to be easily scalable. Overall we hope this dual fundamental and applied approach to be of great help in facilitating the implementation of Li-rich materials in the next generation of Li-ion batteries.

\section{ASSOCIATED CONTENT}

Supporting Information. 10 figures showing SEM images, XRD and galvanostatic cycling studies of Li-rich NMC. This material is available free of charge via the Internet at http://pubs.acs.org.

\section{AUTHOR INFORMATION}

\section{Corresponding Author}

* E-mail: jean-marie.tarascon@college-de-france.fr

\section{ORCID}

Vanessa Pimenta: 0000-0001-7409-1310

Mariyappan Sathiya: 0000-0003-2851-5906 
Dmitry Batuk: 0000-0002-6384-6690

Domitille Giaume: 0000-0001-7369-0872

Sophie Cassaignon : 0000-0001-6599-3718

\section{Author Contributions}

All authors have given approval to the final version of the manuscript.

\section{ACKNOWLEDGMENT}

The authors acknowledge the French Research Network on Electrochemical Energy Storage (RS2E) for the financial support. The authors are thankful to Dr. G. Rousse for the help on Rietveld refinements.

(Should we need to acknowledge Deliredox particularly? Dmitry's ARPEMA project?)

\section{REFERENCES}

(1) Armand, M.; Tarascon, J-M. Building better batteries. Nature 2008, 451, 652-657.

(2) Yabuuchi, N.; Ohzuku, T. Novel lithium insertion material of $\mathrm{LiCo}_{1 / 3} \mathrm{Ni}_{1 / 3} \mathrm{Mn}_{1 / 3} \mathrm{O}_{2}$ for advanced lithium-ion batteries. J. Power Sources 2003, 119, 171-174.

(3) Sathiya, M.; Rousse, G.; Ramesha, K.; Laisa, C. P.; Vezin, H.; Sougrati, M. T.; Doublet, M-L.; Foix, D.; Gonbeau, D.; Walker, W.; Prakash, A. S.; Ben Hassine, M.; Dupont, L.; Tarascon, J-M. Reversible anionic redox chemistry in high-capacity layered-oxide electrodes. Nature Mater. 2012, 12, 827-835.

(4) Koga, H.; Croguennec, L.; Ménétrier, M.; Douhil, K.; Belin, S.; Bourgeois, L.; Suard, E.; Weill, F.; Delmas,

C. Reversible Oxygen Participation to the Redox Processes Revealed for $\mathrm{Li}_{1.20} \mathrm{Mn}_{0.54} \mathrm{Co}_{0.13} \mathrm{Ni}_{0.13} \mathrm{O}_{2}$. J. Electrochem. Soc. 2013, 160, A786-A792.

(5) Hong, J.; Gwon, H.; Jung, S.K.; Ku, K.; Kang, K. Lithium-Excess Layered Cathodes for Lithium Rechargeable Batteries. J. Electrochem. Soc. 2015, 162, A2447-A2467.

(6) Hy, S.; Liu, H.; Zhang, M.; Qian, D.; Hwang, B.J.; Meng, Y. S. Performance and design considerations for lithium excess layered oxide positive electrode materials for lithium ion batteries. Energy Environ. Sci. 2016, 9, $1931-1954$.

(7) Manthiram, A.; Knight, J.C.; Myung, S.T.; Oh, S.M.; Sun, Y.K. Nickel-Rich and Lithium-Rich Layered Oxide Cathodes: Progress and Perspectives. Adv. Energy Mater. 2016, 6, 1501010. 
(8) Wu, Y.; Manthiram, A. High Capacity, Surface-Modified Layered $\mathrm{Li}\left[\mathrm{Li}_{(1-x) / 3} \mathrm{Mn}_{(2-x) / 3} \mathrm{Ni}_{\mathrm{x} / 3} \mathrm{Co}_{\mathrm{x} / 3}\right] \mathrm{O}_{2}$ Cathodes with Low Irreversible Capacity Loss, Electrochem. Solid State Lett. 2006, 9, A221-A224.

(9) Liu, H.; Qian, D.; Verde M.G.; Zhang, M.; Baggetto, L;. An, K.; Chen, Y.; Carroll, K. J.; Lau, D.; Chi, M.; Veith, G. M.; Meng, Y. S. Understanding the Role of $\mathrm{NH}_{4} \mathrm{~F}$ and $\mathrm{Al}_{2} \mathrm{O}_{3}$ Surface Co-modification on LithiumExcess Layered Oxide $\mathrm{Li}_{1.2} \mathrm{Ni}_{0.2} \mathrm{Mn}_{0.6} \mathrm{O}_{2}$. ACS Appl. Mater. Interfaces 2015, 7, 19189-19200.

(10) Nayak, P.K.; Grinblat, J.; Levi, M.; Aurbach, D. Electrochemical and structural characterization of carbon coated $\mathrm{Li}_{1.2} \mathrm{Mn}_{0.56} \mathrm{Ni}_{0.16} \mathrm{Co}_{0.08} \mathrm{O}_{2}$ and $\mathrm{Li}_{1.2} \mathrm{Mn}_{0.6} \mathrm{Ni}_{0.2} \mathrm{O}_{2}$ as cathode materials for Li-ion batteries. Electrochim. Acta 2014, 137, 546-556.

(11) Prakasha, K. R.; Sathish, M.; Bera, P.; Prakash, A.S. Mitigating the Surface Degradation and Voltage Decay of $\mathrm{Li}_{1.2} \mathrm{Ni}_{0.13} \mathrm{Mn}_{0.54} \mathrm{Co}_{0.13} \mathrm{O}_{2}$ Cathode Material through Surface Modification Using $\mathrm{Li}_{2} \mathrm{ZrO}_{3}$. ACS Omega 2017, 2, 2308-2316.

(12) Wang, S.; Li, Y.; Wu, J.; Zheng, B.; McDonald, M. J.; Yang, Y. Toward a stabilized lattice framework and surface structure of layered lithium-rich cathode materials with Ti modification. Phys. Chem. Chem. Phys. 2015, 17, 10151-10159.

(13) Wang, Y. L.; Huang, X.; Li, F.; Cao, J. S.; Ye, S. H. Enhanced high rate performance of $\mathrm{Li}\left[\mathrm{Li}_{0.17} \mathrm{Ni}_{0.2} \mathrm{Co}_{0.05} \mathrm{Mn}_{0.58-x} \mathrm{Al}_{x}\right] \mathrm{O}_{2-0.5 x}$ cathode material for lithium-ion batteries. RSC Adv. 2015, 5, 4965149656.

(14) Li, L.; Song, B.H.; Chang, Y.L.; Xi, H.; Yang, J.R.; Lee, K.S.; Lu, L. Retarded phase transition by fluorine doping in Li-rich layered $\mathrm{Li}_{1.2} \mathrm{Mn}_{0.54} \mathrm{Ni}_{0.13} \mathrm{Co}_{0.13} \mathrm{O}_{2}$ cathode material. J. Power Sources 2015, 283, 162-170.

(15) Xiang, Y.; Yin, Z.; Zhang, Y.; Li, X. Effects of synthesis conditions on the structural and electrochemical properties of the Li-rich material $\mathrm{Li}\left[\mathrm{Li}_{0.2} \mathrm{Ni}_{0.17} \mathrm{Co}_{0.16} \mathrm{Mn}_{0.47}\right] \mathrm{O}_{2}$ via the solid-state method. Electrochim. Acta 2013, 91, 214-218.

(16) Liu, J.; Chen, L.; Hou, M.; Wang, F.; Che, R.; Xia, Y. General synthesis of $x \mathrm{Li}_{2} \mathrm{MnO}_{3} \cdot(1-x) \mathrm{LiMn}_{1 / 3} \mathrm{Ni}_{1 / 3} \mathrm{Co}_{1 / 3} \mathrm{O}_{2}$ nanomaterials by a molten-salt method: towards a high capacity and high power cathode for rechargeable lithium batteries. J. Mater. Chem. 2012, 22, 25380-25387.

(17) Fu, F.; Deng, Y.P.; Shen, C.H.; Xu, G.L.; Peng, X.X.; Wang, Q.; Xu, Y.F.; Fang, J.C.; Huang, L.; Sun, S.G. A hierarchical micro/nanostructured $0.5 \mathrm{Li}_{2} \mathrm{MnO}_{3} \cdot 0.5 \mathrm{LiMn}_{0.4} \mathrm{Ni}_{0.3} \mathrm{Co}_{0.3} \mathrm{O}_{2}$ material synthesized by solvothermal route as high rate cathode of lithium ion battery. Electrochem. Commun. 2014, 44, 54-58.

(18) Zheng, F.; Ou, X.; Pan, Q.; Xiong, X.; Yang, C.; Liu, M. The effect of composite organic acid (citric acid \& tartaric acid) on microstructure and electrochemical properties of $\mathrm{Li}_{1.2} \mathrm{Mn}_{0.54} \mathrm{Ni}_{0.13} \mathrm{Co}_{0.13} \mathrm{O}_{2}$ Li-rich layered oxides. J. Power Sources, 2017, 346, 31-39. 
(19) Lim, J.H.; Bang, H.; Lee, K.S.; Amine, K.; Sun, Y.K. Electrochemical characterization of $\mathrm{Li}_{2} \mathrm{MnO}_{3}-$ $\mathrm{Li}\left[\mathrm{Ni}_{1 / 3} \mathrm{Co}_{1 / 3} \mathrm{Mn}_{1 / 3}\right] \mathrm{O}_{2}-\mathrm{LiNiO}_{2}$ cathode synthesized via co-precipitation for lithium secondary batteries. J. Power Sources 2009, 189, 571-575.

(20) Park, S.H.; Kang, S.-H.; Belharouak, I.; Sun, Y.K.; Amine, K. Physical and electrochemical properties of spherical $\mathrm{Li}_{1+\mathrm{x}}\left(\mathrm{Ni}_{1 / 3} \mathrm{Co}_{1 / 3} \mathrm{Mn}_{1 / 3}\right)_{1-\mathrm{x}} \mathrm{O}_{2}$ cathode materials. J. Power Sources 2008, 177, 177-183.

(21) van Bommel, A.; Dahn, J. R. Analysis of the Growth Mechanism of Coprecipitated Spherical and Dense Nickel, Manganese, and Cobalt-Containing Hydroxides in the Presence of Aqueous Ammonia. Chem. Mater. 2009, 21, 1500-1503.

(22) van Bommel, A.; Dahn, J. R. Synthesis of Spherical and Dense Particles of the Pure Hydroxide Phase $\mathrm{Ni}_{1 / 3} \mathrm{Mn}_{1 / 3} \mathrm{Co}_{1 / 3}(\mathrm{OH})_{2}$. J. Electrochem. Soc. 2009, 156, A362-A365.

(23) Sun, Y.K.; Myung, S.T.; Kim, M.H.; Prakash, J.; Amine, K. Synthesis and characterization of $\mathrm{Li}\left[\left(\mathrm{Ni}_{0.8} \mathrm{Co}_{0.1} \mathrm{Mn}_{0.1}\right)_{0.8}\left(\mathrm{Ni}_{0.5} \mathrm{Mn}_{0.5}\right)_{0.2}\right] \mathrm{O}_{2}$ with the microscale core-shell structure as the positive electrode material for lithium batteries. J. Am. Chem. Soc. 2005, 127, 13411-13418.

(24) Dai, D.; Wang, B.; Li, B.; Li, F.; Wang, X.; Tang, H.; Chang, Z. Li-rich layered $\mathrm{Li}_{1.2} \mathrm{Mn}_{0.54} \mathrm{Ni}_{0.13} \mathrm{Co}_{0.13} \mathrm{O}_{2}$ derived from transition metal carbonate with a micro-nanostructure as a cathode material for highperformance Li-ion batteries. RSC Adv. 2016, 6, 96714-96720.

(25) Du, C.Q.; Zhang, F.; Ma, C.X.; Wu, J.W.; Tang, Z.Y.; Zhang, X.H.; Qu, D. Synthesis and electrochemical properties of $\mathrm{Li}_{1.2} \mathrm{Mn}_{0.54} \mathrm{Ni}_{0.13} \mathrm{Co}_{0.13} \mathrm{O}_{2}$ cathode material for lithium-ion battery. Ionics 2016, 22, 209-218.

(26) Fu, F.; Yao, Y.; Wang, H.; Xu, G-L.; Amine, K.; Sun, S-G.; Shao, M. Structure dependent electrochemical performance of Li-rich layered oxides in lithium-ion batteries. Nano Energy 2017, 35, 370378.

(27) He, X.; Wang, J.; Kloepsch, R.; Krueger, S.; Jia, H.; Liu, H.; Vortmann, B.; Li, J. Enhanced electrochemical performance in lithium ion batteries of a hollow spherical lithium-rich cathode material synthesized by a molten salt method. Nano Res. 2014, 7, 110-118.

(28) Remith, P.; Kalaiselvi, N. $\mathrm{Li}_{1.2} \mathrm{Mn}_{0.54} \mathrm{Ni}_{0.13} \mathrm{Co}_{0.13} \mathrm{O}_{2}$ microspheres constructed by hierarchically arranged nanoparticles as lithium battery cathode with enhanced electrochemical performance. Nanoscale 2014, 6, 14724-14732.

(29) Lou, M.; Zhong, H.; Yu, H.T.; Fan, S-S.; Xie, Y.; Yi, T.F. Li $\mathrm{Li}_{1.2} \mathrm{Mn}_{0.54} \mathrm{Ni}_{0.13} \mathrm{Co}_{0.13} \mathrm{O}_{2}$ hollow hierarchical microspheres with enhanced electrochemical performances as cathode material for lithium-ion battery application. Electrochim. Acta 2017, 237, 217-226. 
(30) Zhang, L.; Borong, W.; Ning, L.; Feng, W. Hierarchically porous micro-rod lithium-rich cathode material $\mathrm{Li}_{1.2} \mathrm{Mn}_{0.54} \mathrm{Ni}_{0.13} \mathrm{Co}_{0.13} \mathrm{O}_{2}$ for high performance lithium-ion batteries. Electrochim. Acta 2014, 118, 67-74.

(31) Jin, X.; Xu, Q.; Yuan, X.; Zhou, L.; Xia, Y. Synthesis, characterization and electrochemical performance of $\mathrm{Li}\left[\mathrm{Li}_{0.2} \mathrm{Mn}_{0.54} \mathrm{Ni}_{0.13} \mathrm{Co}_{0.13}\right] \mathrm{O}_{2}$ cathode materials for lithium-ion batteries. Electrochim. Acta 2013, 114, 605610.

(32) J. Rodríguez-Carvajal, FULLPROF Suite www.ill.eu/sites/fullprof/

(33) Rodríguez-Carvajal, J. Recent advances in magnetic structure determination by neutron powder diffraction. Phys. B: Condens. Matter. 1993, 192, 55-69.

(34) Wayne Rasband, ImageJ software, https://imagej.nih.gov/ij/

(35) Koga, H.; Croguennec, L.; Mannessiez, P.; Ménétrier, M.; Weill, F.; Bourgeois, L.; Duttine, M.; Suard, E.; Delmas, C.; $\mathrm{Li}_{1.20} \mathrm{Mn}_{0.54} \mathrm{Co}_{0.13} \mathrm{Ni}_{0.13} \mathrm{O}_{2}$ with Different Particle Sizes as Attractive Positive Electrode Materials for Lithium-Ion Batteries: Insights into Their Structure. J. Phys. Chem. C 2012, 116, 13497-13506.

(36) Housecroft, C. E. and Sharpe, A. G. Inorganic Chemistry, Pearson Education Limited, $2^{\text {nd }}$ Edition, 2005 p.631

(37) Cheng, H.; Zhang, X.; Song, H. Morphological Investigation of Calcium Carbonate during Ammonification-Carbonization Process of Low Concentration Calcium Solution. J. Nanomater. 2014, 2014, 503696.

(38) Xiao, Y.; Liu, S.; Li, F.; Zhang, A.; Zhao, J.; Fang, S.; Jia, D. 3D Hierarchical $\mathrm{Co}_{3} \mathrm{O}_{4}$ Twin-Spheres with an Urchin-Like Structure: Large-Scale Synthesis, Multistep-Splitting Growth, and Electrochemical Pseudocapacitors. Adv. Funct. Mat. 2012, 22, 4052-4059.

(39) Bai, J.; Li, X.; Liu, G.; Qian, Y.; Xiong, S. Unusual Formation of $\mathrm{ZnCo}_{2} \mathrm{O}_{4}$ 3D Hierarchical Twin Microspheres as a High-Rate and Ultralong-Life Lithium-Ion Battery Anode Material. Adv. Funct. Mat. 2014, 24, 3012-3020.

(40) Jena, A.; Lee, C.H.; Pang, W.K.; Peterson, V. K.; Sharma, N.; Wang, C.C.; Song, Y.F.; Lin, C.C.; Chang, H.; Liu, R.S. Capacity Enhancement of the Quenched Li-Ni-Mn-Co Oxide High-voltage Li-ion Battery Positive Electrode. Electrochim. Acta 2017, 236, 10-17.

(41) Cao, K.; Shen, T.; Wang, K.; Chen, D.; Wang, W. Influence of different lithium sources on the morphology, structure and electrochemical performances of lithium-rich layered oxides. Ceram. Int. 2017, 43, 8694-8702. 
(42) Wei, X.; Zhang, S.; Yang, P.; Li, H.; Wang, S.; Ren, Y.; Xing, Y.; Meng, J. Effects of Lithium Content on Structure and Electrochemical Properties of Li-rich Cathode Material $\mathrm{Li}_{1.2+\times} \mathrm{Mn}_{0.54} \mathrm{Ni}_{0.13} \mathrm{Co}_{0.13} \mathrm{O}_{2}$. Int. J. Electrochem. Sci. 2017, 12, 5636-5645.

(43) Wang, J.; Yuan, G.; Zhang, M.; Qiu, B.; Xia, Y.; Liu, Z. The structure, morphology, and electrochemical properties of $\mathrm{Li}_{1+x} \mathrm{Ni}_{1 / 6} \mathrm{Co}_{1 / 6} \mathrm{Mn}_{4 / 6} \mathrm{O}_{2.25+\times / 2}(0.1 \leq \mathrm{x} \leq 0.7)$ cathode materials. Electrochim. Acta 2012, 66, 61-66. (44) Liu, J.; Hou, M.; Yi, J.; Guo, S.; Wang, C.; Xia, Y. Improving the electrochemical performance of layered lithium-rich transition-metal oxides by controlling the structural defects. Energy Environ. Sci. 2014, 7, 705714.

(45) Jiang, Y.; Yang, Z.; Luo, W.; Hu, X.; Huang, Y. Hollow 0.3 $\mathrm{Li}_{2} \mathrm{MnO}_{3} \cdot 0.7 \mathrm{LiNi} \mathrm{i}_{0.5} \mathrm{Mn}_{0.5} \mathrm{O}_{2}$ microspheres as a high-performance cathode material for lithium-ion batteries. Phys. Chem. Chem. Phys. 2013, 15, 29542960.

(46) Genevois, C.; Koga, H.; Croguennec, L.; Ménétrier, M.; Delmas, C.; Weill, F. Insight into the Atomic Structure of Cycled Lithium-Rich Layered Oxide $\mathrm{Li}_{1.2} \mathrm{Mn}_{0.54} \mathrm{Ni}_{0.13} \mathrm{Co}_{0.13} \mathrm{O}_{2}$ Using HAADF STEM and Electron Nanodiffraction. J. Phys. Chem. C 2015, 119, 75-83.

(47) Song, B.; Liu, Z.; On Lai, M.; Lu, L. Structural evolution and the capacity fade mechanism upon longterm cycling in Li-rich cathode material. Phys. Chem. Chem. Phys. 2012, 14, 12875-12883.

(48) Yan, P.; Zheng, J.; Gu, M.; Xiao, J.; Zhang, J.G.; Wang, C.M. Intragranular cracking as a critical barrier for high-voltage usage of layer-structured cathode for lithium-ion batteries. Nat. Commun. 2017, 8, 14101.

(49) Liu, H.; Wolf, M.; Karki, K.; Yu, Y.S.; Stach, E. A.; Cabana, J.; Chapman, K.W.; Chupas, P.J. Intergranular Cracking as a Major Cause of Long-Term Capacity Fading of Layered Cathodes. Nano Lett. 2017, 17, 3452-3457.

(50) Yu, L.; Qiu, W.; Lian, F.; Liu, W.; Kang, X.; Huang, J. Comparative study of layered $0.65 \mathrm{Li}\left[\mathrm{Li}_{1 / 3} \mathrm{Mn}_{/ 3}\right] \mathrm{O}_{2} \cdot 0.35 \mathrm{LiMO}_{2}\left(\mathrm{M}=\mathrm{Co}, \mathrm{Ni}_{1 / 2} \mathrm{Mn}_{1 / 2}\right.$ and $\left.\mathrm{Ni}_{1 / 3} \mathrm{Co}_{1 / 3} \mathrm{Mn}_{1 / 3}\right)$ cathode materials. Mater. Lett. 2008, 62, 3010-3013.

(51) Xiao, L.; Xiao, J.; Yu, X.; Yan, P.; Zheng, J.; Engelhard, M.; Bhattacharya, P.; Wang, C.; Yang, X.Q.; Zhang, J.G. Effects of structural defects on the electrochemical activation of $\mathrm{Li}_{2} \mathrm{MnO}_{3}$. Nano Energy 2015 , $16,143-151$.

(52) Assat, G.; Delacourt, C.; Dalla Corte, D. A.; Tarascon, J-M. Practical Assessment of Anionic Redox in Li-Rich Layered Oxide Cathodes: A Mixed Blessing for High Energy Li-lon Batteries. J. Electrochem. Soc. 2016, 163, A2965-A2976. 
(53) Sathiya, M.; Leriche, J.-B.; Salager, E.; Gourier, D.; Tarascon, J-M.; Vezin, H. Electron paramagnetic resonance imaging for real-time monitoring of Li-ion batteries. Nature Comm. 2015, 6, 6276. 
Table of contents

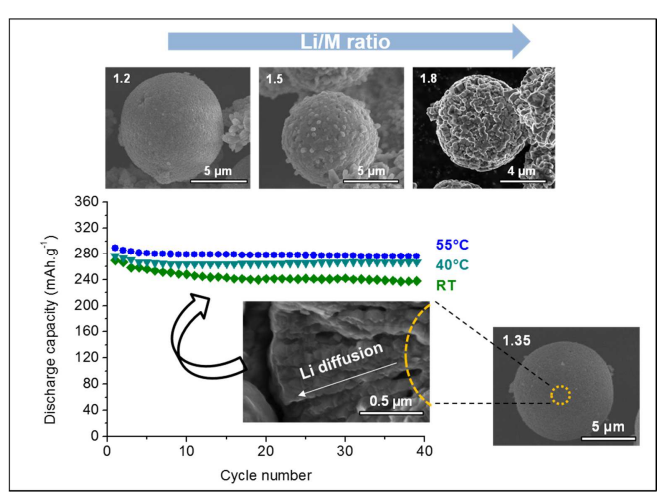

